\title{
Supplemental Information for Engineering a cytochrome P450 for demethylation of lignin-derived aromatic aldehydes
}

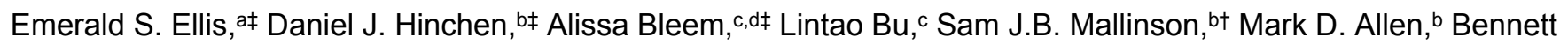
R. Streit, ${ }^{a}$ Melodie M. Machovina, ${ }^{\text {al }}$ Quinlan V. Doolin, ${ }^{a}$ William E. Michener, ${ }^{c}$ Christopher W. Johnson, ${ }^{c}$ Brandon C. Knott, ${ }^{c}$ Gregg T. Beckham, ${ }^{\mathrm{c}, \mathrm{d} *}$ John E. McGeehan, ${ }^{\mathrm{b} *}$ Jennifer L. DuBois ${ }^{a^{*}}$

a. Department of Chemistry and Biochemistry, Montana State University, 103 Chemistry and Biochemistry Building, PO Box 173400, Bozeman MT 59717 United States

b. Centre for Enzyme Innovation, School of Biological Sciences, Institute of Biological and Biomedical Sciences, University of Portsmouth, PO1 2DY, United Kingdom

c. Renewable Resources and Enabling Sciences Center, National Renewable Energy Laboratory, Golden CO 80401 United States

d. Center for Bioenergy Innovation, Oak Ridge National Laboratory, Oak Ridge TN 37830 United States

${ }^{*}$ Corresponding authors

$\ddagger$ Denotes equal contribution

*Email: jennifer.dubois1@montana.edu; john.mcgeehan@port.ac.uk; gregg.beckham@nrel.gov

\section{Table of Contents}

\section{Section 1: Detailed Experimental Methods}

Protein expression and purification 3

Measurements of $K_{D} s$ for guaiacol, $p$-vanillin, and $o$-vanillin 3

Measurement of percent-coupling of NADH consumption to formaldehyde production and substrate demethylation 3

Formaldehyde quantification assay 3

Substrate quantification by HPLC 4

Measurement of steady state reactivity 4

Crystallography 4

Molecular dynamics simulations 4

Strain construction 5

Shake flask cultivations 5

Analytical methods for metabolite quantification 5

\section{Section 2: Figures}

Figure S1. General topology of the GcoA active site 6

Figure S2. Spectroscopic changes reflecting conversion from high- to low-spin $\mathrm{Fe}(\mathrm{III})$ were used to measure the binding affinity $\left(K_{D}\right)$ of $G c o A$ variants for guaiacol and vanillins.

Figure S3. Representative measurements of substrate consumption and product formation in the oxidation reactions catalyzed by GcoA-F169S and -T269S 10

Figure S4. Analysis of products of reactions between GcoAB variants and vanillin isomers, by comparison with known standards 11

Figure S5. Representative Michaelis-Menten plots. 14 
Figure S6. Electron density of GcoA mutant active sites.

Figure S7. Ligand binding comparisons to preferred wildtype substrate guaiacol. 16

Figure S8. Hydrogen bond network around heme propionate.

Figure S9. Starting configuration for T296S molecular dynamics (MD) simulation with bound $p$-vanillin.18

Figure S10. Dynamic evolution of hydrogen bond partners in T296S GcoA with vanillin via molecular dynamics simulation.

Figure S11. Binding mode of ligand in molecular dynamics simulations. 20

Figure S12. R298 interactions with heme propionate in molecular dynamics simulations. 21

Figure S13. Active site water structure and dynamics from molecular dynamics simulations. 22

Figure S14. Growth curves for $P$. putida KT2440 wild-type on vanillin isomers. 23

Figure S15. Growth dynamics of engineered $P$. putida strains versus KT2440 wild-type. 24

Figure S16. Mole balance of metabolites in engineered $P$. putida strains. 25

Figure S17. Growth of $P$. putida strain ACB087 under oxidative stress conditions. 26

\section{Section 3: Tables}

Table S1. Catalytic efficiencies, ligand affinities, and kinetic properties of GcoA and its variants. 27

Table S2. X-ray tables for GcoA-T296X guaiacol-bound structures

Table S3. X-ray tables for GcoA-T296X p-vanillin-bound structures 29

Table S4. X-ray tables for GcoA-F169X o-vanillin-bound structures 30

Table S5. Strain construction details 31

Table S6. Primers used in construction of plasmids 32

Table S7. Plasmids and construction details 33

Section 4: References 34

[[page break here $\rightarrow]$ ] 


\section{Section 1: Detailed Experimental Methods}

\section{Protein expression and purification}

GcoA and variants thereof were expressed as described previously. ${ }^{1}$ Briefly, codon optimized genes for GcoA, and site directed variants were expressed from a pET based plasmid in E.coli BL21DE3 cells. Single colonies of cells were inoculated in $10 \mathrm{ml}$ Terrific Broth (TB) supplemented with the appropriate antibiotic and grown with shaking at $37^{\circ} \mathrm{C}$ until saturation. The saturated solutions were inoculated $1: 100$ in $100 \mathrm{ml}$ of TB + antibiotic overnight at 37 ${ }^{0} \mathrm{C}$ with shaking at $200 \mathrm{rpm}$. Six fernbach flasks each containing $1 \mathrm{~L}$ of TB + antibiotic were inoculated 1:100 (v/v) with the overnight culture and grown at $37{ }^{\circ} \mathrm{C}$ with $200 \mathrm{rpm}$ shaking to an $\mathrm{OD}_{600}=0.4-0.6$. The cells were then induced via the addition of IPTG to a concentration of $0.1 \mathrm{mM}$. The cells were left at $20^{\circ} \mathrm{C}$ with $200 \mathrm{rpm}$ shaking for $\sim 16$ hours with subsequent harvesting of the cells via centrifugation at $5,000 \times \mathrm{g}$ and freezing of the wet cell paste in liquid nitrogen. Frozen cells were stored at $-80{ }^{\circ} \mathrm{C}$. Typical yields were $10-20 \mathrm{~g} / \mathrm{L}$ wet cell paste.

\section{Measurements of $K_{D} s$ for guaiacol, $p$-vanillin, and o-vanillin}

Measurement of binding affinities of WT, T296S, F169S, and F169A/T296S GcoA for guaiacol, $p$-vanillin, and ovanillin were carried out by monitoring characteristic changes in the UV/vis spectrum of the enzyme upon substrate binding, which are induced by conversion of the heme from a low-spin to a high-spin state. Titrations were performed by adding $0.6 \mathrm{ml}$ of a $5-10 \mu \mathrm{M}$ enzyme solution (100 mM HEPES pH $7.5+100 \mathrm{mM} \mathrm{NaCl}$ ) to a cuvette and titrating with small volumes (1-5 $\mu \mathrm{l})$ of ligand from a $0.250-10 \mathrm{mM}$ stock. A spectrum was measured after each addition of ligand. The absorbance data was corrected for dilution and the change in absorbance at either $388 \mathrm{~nm}$ (guaiacol) or $570 \mathrm{~nm}$ (o- and $p$-vanillin) was plotted as a function of substrate concentration and fit to Equation S1:

$$
\text { Equation S1: } \quad \Delta A b s=\frac{\Delta A b s_{\max }[S]}{[S]+K_{d}}
$$

where $\Delta \mathrm{Abs}$ is the change in absorbance at a given wavelength, $\Delta \mathrm{Abs}_{\max }$ is the theoretical change in absorbance if the enzyme is fully bound by substrate, $[S]$ is the substrate concentration, and $K_{d}$ is the equilibrium binding constant. Due to the tight binding of guaiacol by WT GcoA a hyperbolic form of the equation taking in into account the tight binding enzyme ([E]) was used to more accurately determine the $K_{d}$ for that substrate. The equation used was as follows:

$$
\text { Equation S2: } \quad \Delta A b s=\frac{\Delta A b s_{\max }}{2[E]}\left(\left(K_{d}+[E]+[S]\right)-\sqrt{\left(K_{d}+[E]+[S]\right)^{2}-(2[S][E])^{2}}\right)
$$

For each enzyme/substrate pair at least two titrations were carried out and the average results for each $K_{\mathrm{d}}$ are reported in Table S1.

\section{Measurement of percent-coupling of NADH consumption to formaldehyde production and substrate demethylation}

For each combination of substrate and GcoA variant, a single reaction mixture containing $0.2-0.5 \mu \mathrm{M} G \mathrm{coAB}, 100$ $\mu \mathrm{g} / \mathrm{ml}$ catalase, and $250 \mu \mathrm{M} \mathrm{NADH}$ was prepared in room temperature, air-saturated buffer $(25 \mathrm{mM}$ HEPES, 100mM $\mathrm{NaCl}, \mathrm{pH} 7.5$; up to $\left.210 \mu \mathrm{M} \mathrm{O}_{2}\right)$. Each reaction was initiated with a small volume $(0.25-0.5 \mu \mathrm{L})$ of substrate to a final concentration of $250 \mu \mathrm{M}$ (guaiacol, o-vanillin) or $100 \mu \mathrm{M}$ ( $p$-vanillin). The consumption of NADH over time was monitored by UV/Vis absorbance spectroscopy for 45 minutes or until there was no further change observed in the absorbance spectrum. The reaction was then quenched with concentrated $\mathrm{H}_{2} \mathrm{SO}_{4}$. The change in absorbance at $340 \mathrm{~nm}$ was used to determine the amount of NADH consumed, given an extinction coefficient of $6.22 \mathrm{mM}^{-1} \mathrm{~cm}^{-1} .2$ Duplicate samples of the reaction mixture were removed for quantification of formaldehyde via the tryptophanformaldehyde detection assay (see below), and the amount of substrate consumed was determined by HPLC analysis (see below). The percent-coupling of $\mathrm{NADH}$ consumption to formaldehyde production and substrate demethylation is given by the ratio of the change in formaldehyde or substrate concentration to the change in NADH concentration.

\section{Formaldehyde quantification assay}

The amount of formaldehyde produced by $\mathrm{GcoAB}$ was quantified using a tryptophan-based colorimetric assay adapted from the method of Chrastil and Wilson. ${ }^{3}$ The assay reagent contains a 4:4:1 mixture of $90 \% \mathrm{H}_{2} \mathrm{SO}_{4}, 0.1$ $\%(w / v)$ tryptophan in $50 \% \mathrm{EtOH}$, and $1 \%(\mathrm{w} / \mathrm{v}) \mathrm{FeCl}_{3}$, and was prepared daily by combining the $\mathrm{H}_{2} \mathrm{SO}_{4}$ and 
tryptophan solutions and incubating the mixture on ice until cool before adding the $\mathrm{FeCl}_{3}$ solution. A standard curve was generated each time the assay was performed using $200 \mu \mathrm{L}$ formaldehyde standards in the concentration range of $0-300 \mu \mathrm{M}$, which were freshly prepared in reaction buffer $(25 \mathrm{mM} \mathrm{HEPES}, 100 \mathrm{mM} \mathrm{NaCl}, \mathrm{pH} 7.5)$. To each $200 \mu \mathrm{L}$ standard and sample was added $440 \mu \mathrm{L}$ of assay reagent. The mixture was incubated at $70{ }^{\circ} \mathrm{C}$ for 1 hour, then cooled to room temperature before the absorbance at $575 \mathrm{~nm}$ was measured. The amount of formaldehyde produced by each combination of GcoAB and substrate was determined by comparison to the standard curve.

\section{Substrate quantification by HPLC}

Substrate consumption was quantified using an Agilent 1100 LC system (Agilent Technologies, Santa Clara, CA) equipped with a G1315A diode array detector (DAD). Each sample and standard was injected at a volume of $25 \mu \mathrm{L}$ onto a Waters $\mathrm{C} 18$ column $\left(4.6 \times 150 \mathrm{~mm}, 5 \mu \mathrm{m}\right.$ particle diameter) maintained at $37^{\circ} \mathrm{C}$. The mobile phase used to separate the analytes of interest was water $(A) / a c e t o n i t r i l e(B)$, each with $0.1 \%$ trifluoroacetic acid. The separation was carried out using a flow rate of $1.5 \mathrm{ml} / \mathrm{min}$, with the following program: $0-2 \mathrm{~min}, 5 \% \mathrm{~B}$ (isocratic); $2-8 \mathrm{~min}, 5$ to $50 \%$ B (gradient); 8-11 min, 95\% B (isocratic); $11-13 \mathrm{~min}, 5 \% \mathrm{~B}$ (isocratic). A DAD wavelength of $275 \mathrm{~nm}$ was used for analysis of the analytes of interest. A minimum of 3-5 calibration levels was used with an $r^{2}$ coefficient of 0.99 or better for each analyte.

\section{Measurement of steady state reactivity}

The steady state kinetics for demethylation of guaiacol, $p$-vanillin, and $o$-vanillin by GcoA variants were measured by monitoring the consumption of substrate discontinuously by HPLC (see above). In the presence of $100 \mu \mathrm{g} / \mathrm{ml}$ catalase, $0.5 \mu \mathrm{M}$ GcoAB was incubated with $20-500 \mu \mathrm{M}$ substrate in room temperature, air-saturated buffer $(25$ $\mathrm{mM}$ HEPES, $100 \mathrm{mM} \mathrm{NaCl}, \mathrm{pH} 7.5$; up to $210 \mu \mathrm{M} \mathrm{O}_{2}$ ). After the reaction was initiated by addition of $300 \mu \mathrm{M} \mathrm{NADH}$, a $50 \mu \mathrm{L}$ sample was removed every $30 \mathrm{~s}$ for $2 \mathrm{~min}$. For each reaction, a $50 \mu \mathrm{L}$ sample was taken from a duplicate reaction mixture containing no GcoAB to give a $0 \mathrm{~s}$ timepoint. Each sample was quenched with $\mathrm{H}_{2} \mathrm{SO}_{4}$ immediately, and then stored at $4{ }^{\circ} \mathrm{C}$ in the HPLC autosampler unit. A progress of reaction curve was generated for each reaction and fit to a line equation to determine the initial rate of substrate consumption relative to the concentration of $G \operatorname{coAB}$ $\left(v_{i} /[E]\right)$. Each reaction was performed at least in triplicate and the results averaged. Rate plots were fit to Equation S3:

$$
\text { Equation S3: } \quad v_{i} /_{[E]}=\frac{k_{\text {cat }}[S]}{[S]+K_{m}}
$$

where [S] is the substrate concentration, $\mathrm{k}_{\text {cat }}$ is the maximum velocity of reaction when the enzyme is saturated with substrate, and $\mathrm{K}_{\mathrm{m}}$ is the substrate concentration that gives $0.5 \mathrm{k}_{\text {cat }}$. Michaelis constants are apparent, as the dioxygen and $\mathrm{GcoB}$ concentrations are not known to be saturating.

\section{Crystallography}

Pure protein was buffer exchanged into $10 \mathrm{mM}$ HEPES pH 7.5 and concentrated to $280 \mathrm{uM}$. Crystals were grown in $2.4 \mathrm{M}$ sodium malonate and $200 \mathrm{mM}$ substrate, dissolved in $40 \%$ DMSO where necessary. Crystals were cryocooled directly in liquid nitrogen without further addition of cryoprotectants. All X-ray diffraction data were collected at the Diamond Light Source (Harwell, UK), using beamlines 104 and 103 equipped with Dectris Eiger2 XE $16 \mathrm{M}$ detectors. Data collection statistics are detailed in Tables S1-3. Phases were solved using molecular replacement from the native GcoA structure in complex with guaiacol, PDB ID 5NCB. ${ }^{4}$ Data were processed, phased, and models built and refined using either Xia2 or XDS, ${ }^{5-9}$ the Phenix suite ${ }^{10-12}$ and COOT. ${ }^{13}$ Structural models and electron density figures were produced using PyMOL. ${ }^{14}$

\section{Molecular dynamics simulations}

MD simulations were performed on the following systems: A) WT GcoA with guaiacol bound at the active site; B) WT GcoA with vanillin bound at the active site; C) T296S mutant with vanillin bound at the active site. The previous constructed models of WT GcoA with guaiacol or vanillin bound at the active site ${ }^{15}$ starting with their crystal structures (PDB accession numbers 5NCB for guaiacol and 5OMR for vanillin) were used as the initial conformation. The model of T296S mutant bound with vanillin is generated by mutating threonine to serine manually from the structure of WT GcoA with $p$-vanillin bound (5OMR), as the crystal structure was not yet available at the time the simulations were initiated. Beyond the noted differences in the positioning of residue 296, heme propionate, and substrate, the starting configuration for simulation was very similar to the crystal structure of T296S bound with vanillin (Figure S9). In the subsequent MD simulations, the orientation of the aldehyde group switched to that seen 
in 6CYM within the first $1 \mathrm{~ns}$ and maintained this position through the full simulation. The evolving positioning of S296 was consistent with the static crystal structure and is discussed in more detail in the main text.

The heme group is modelled in the active Compound I state. The protonation states of titratable residues were determined using $\mathrm{H}++$ web server ${ }^{16}$ at $\mathrm{pH}$ 7.5. Five histidine residues (His131, His221, His224, His255, and His343) were doubly protonated with +1 charge, while the remaining histidine residues were kept neutral. $\mathrm{Na}^{+}$ions were added to maintain charge neutrality. Final system sizes were around 74,000 atoms.

The ff14SB Amber force field ${ }^{17}$ was used for the enzyme. Generalized Amber Force Field (GAFF) ${ }^{18-19}$ was used for guaiacol and vanillin, with Restrained Electrostatic Potential (RESP) partial charge ${ }^{20}$ derived using Gaussian $09^{21}$ at the HF/6-31 G(*) level. The parameters for the heme group 22 are those developed by the Cheatham group. All the MD simulations were conducted using NAMD program ${ }^{23}$ with a time-step of $2.0 \mathrm{fs}$. Particle-Mesh Ewald (PME) ${ }^{24}$ method was used for long-range interactions. The cutoff distance for nonbonded interactions was $9 \AA$. The SHAKE algorithm ${ }^{25}$ was used to keep the length of bonds to hydrogen atoms fixed. Langevin thermostat with a collision frequency of $1.0 \mathrm{ps}^{-1}$ was used to maintain the temperature at $300 \mathrm{~K}$. The pressure was kept at $1 \mathrm{~atm}$ using a Nosé-Hoover barostat coupled to a Langevin piston ${ }^{26-27}$ with a damping time of $100 \mathrm{fs}$ and a period of $200 \mathrm{fs}$. Each system was relaxed in the NPT ensemble for 500 ps, followed by 240 ns of production run in the NVT ensemble.

\section{Strain construction}

Methods for the construction of all plasmids, including primer sequences, are provided in Tables S5-S6. Each plasmid contains the gene of interest (or no gene, if used for gene deletion) flanked by two $\sim 1 \mathrm{~kb}$ fragments of DNA with homology to the regions immediately up- and downstream of the desired genomic locus. These fragments were assembled into suicide vectors pK18mobsacB (GenBank: FJ437239.1) or pK18sB (Genbank: MH166772) using NEBuilder HiFi DNA Assembly Master Mix (New England Biolabs, NEB; Ipswich, MA), and the resulting products were transformed into E. coli DH5a F'lq cells (NEB). Plate and liquid cultures were grown in Luria-Bertani (LB) medium supplemented with $50 \mu \mathrm{g} / \mathrm{mL}$ kanamycin, and all plasmid sequences were verified by the method of Sanger (GENEWIZ, Inc.; South Plainfield, NJ). Genomic modifications in P. putida KT2440 (Table S4) were achieved by electroporating the host strain with the desired plasmid and then performing antibiotic selection and sucrose counter-selection as previously described. ${ }^{28-30}$

\section{Shake flask cultivations}

Strains of $P$. putida designed to express CatA-GcoA fusion proteins (ACB059, ACB086, ACB087, and KT2440 as a control) were evaluated in shake flask experiments. Overnight cultures in $15 \mathrm{~mL}$ LB medium were prepared from a single plated colony of each strain. Overnights were diluted 1:15 in $30 \mathrm{~mL}$ of $1 \mathrm{X} \mathrm{M9}$ media $+20 \mathrm{mM}$ glucose in 125 baffled flasks and grown at $30^{\circ} \mathrm{C}$ and $225 \mathrm{rpm}$ for $4 \mathrm{~h} .5 \mathrm{mM}$ IPTG was then added to each culture to induce overexpression of ech-fcs, and the precultures were incubated a further $2 \mathrm{~h}$. For the shake flask experiment, $25 \mathrm{~mL}$ media (1X M9 + $4 \mathrm{mM}$ ferulic acid $+10 \mathrm{mM}$ glucose + $5 \mathrm{mM} \mathrm{IPTG)} \mathrm{in} 125 \mathrm{~mL}$ baffled flasks was inoculated with each preculture to an initial OD600nm of 0.1 . Cultures were grown in triplicate at $30^{\circ} \mathrm{C}$ and $225 \mathrm{rpm}$ for $120 \mathrm{~h}$, with growth monitored by periodic optical density measurements. An additional $10 \mathrm{mM}$ glucose and $2 \mathrm{mM}$ IPTG was added every $24 \mathrm{~h}$ to support growth and promote metabolite turnover. At each time point, $0.8 \mathrm{~mL}$ samples were withdrawn and centrifuged, and supernatants were passed through $0.22-\mu \mathrm{m}$ filters for metabolite analysis.

\section{Analytical methods for metabolite quantification}

Quantitation of samples was performed on an Agilent 1100 LC system (Agilent Technologies, Santa Clara, CA) equipped with a G1315A diode array detector (DAD). Each sample and standard were injected at a volume of 20 $\mu \mathrm{L}$ on a Phenomenex Luna C18(2) column $5 \mu \mathrm{m}, 4.6 \times 150 \mathrm{~mm}$ column (Phenomenex, Torrance, CA). The column temperature was maintained at $45^{\circ} \mathrm{C}$ and the solution used to separate the analytes of interest was $0.16 \%$ formic acid in water (A) / acetonitrile (B). A gradient program was used to separate the analytes of interest: $(A)=100 \%$ and $(B)=0 \%$ at time $t=0 ;(A)=100 \%$ and $(B)=0 \%$ at $t=3 \mathrm{~min} ;(A)=50 \%$ and $(B)=50 \%$ at $t=23 \mathrm{~min} ;(A)=30 \%$ and $(B)=70 \%$ at $t=28 \mathrm{~min} ;(A)=30 \%$ and $(B)=70 \%$ at $t=32 \mathrm{~min} ;(A)=100 \%$ and $(B)=0 \%$ at $t=32.01 \mathrm{~min} ;(A)$ $=100 \%$ and $(B)=0 \%$ at $t=38 \mathrm{~min}$. The flow rate was held constant at $0.650 \mathrm{~mL} \mathrm{~min}^{-1}$ resulting in a run time of 38 minutes. Standards of vanillyl alcohol, protocatechuic acid, protocatechualdehyde, vanillin, vanillic acid, 3,4dihydroxybenzyl alcohol, and ferulic acid were purchased from Sigma Aldrich (Sigma Aldrich, St Louis, MO). Each standard was used to construct a calibration curve between the ranges of $1-500 \mu \mathrm{gL}^{-1}$. A total of four different wavelengths from the UV detector were used to identify and quantitate the analytes of interest. A wavelength of $225 \mathrm{~nm}$ was used for analyte 3,4-dihydroxybenzyl alcohol, $265 \mathrm{~nm}$ for protocatechuic acid and vanillic acid, 280 $\mathrm{nm}$ for vanillyl alcohol, protocatechualdehyde, and vanillin, and finally $325 \mathrm{~nm}$ for analyte ferulic acid. A minimum 
of five calibration levels were used for each analyte with an $r^{2}$ coefficient of 0.995 or better. A check calibration standard (CCS) was analyzed every 10 samples to ensure the integrity of the initial calibration.

\section{Section 2: Figures}

Figure S1
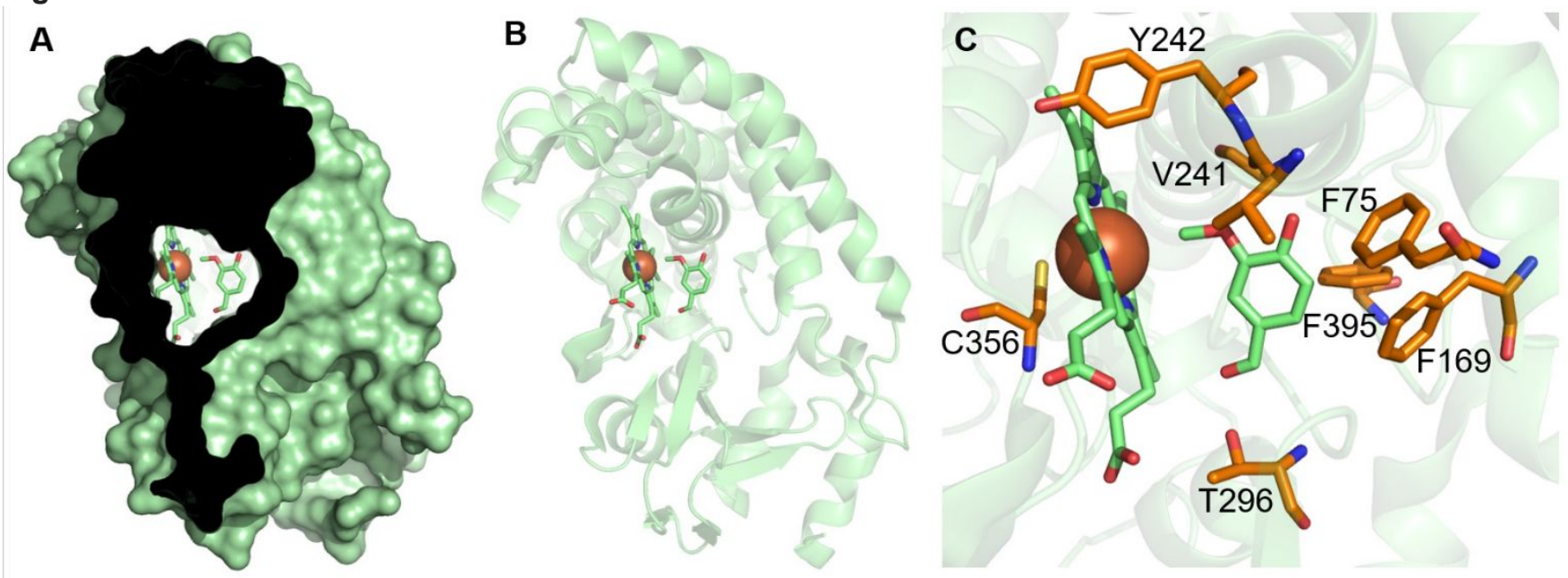

Figure S1. General topology of the GcoA active site. The images provide structural context for the buried active site pocket of GcoA wild-type enzyme in the closed conformation with bound $p$-vanillin (PDB: 5OMR). (A) A surface representation is shown with composite slices through the model to highlight the central buried nature of the active site pocket. The heme and bound vanillin substrate are shown as stick representations. (B) The secondary structure is depicted as cartoons in the same orientation. (C) A close up of the active site with key residues highlighted in orange, including aromatic residues that contribute to the hydrophobic pocket (F75, F169, Y242, F395), residues that hydrogen bond to the ligand (T296, V241) and the cysteine (C356) that interacts with the heme. 
Figure S2

WT GcoA with guaiacol $\left(K_{D}=0.13 \pm 0.02 \mu M\right)$
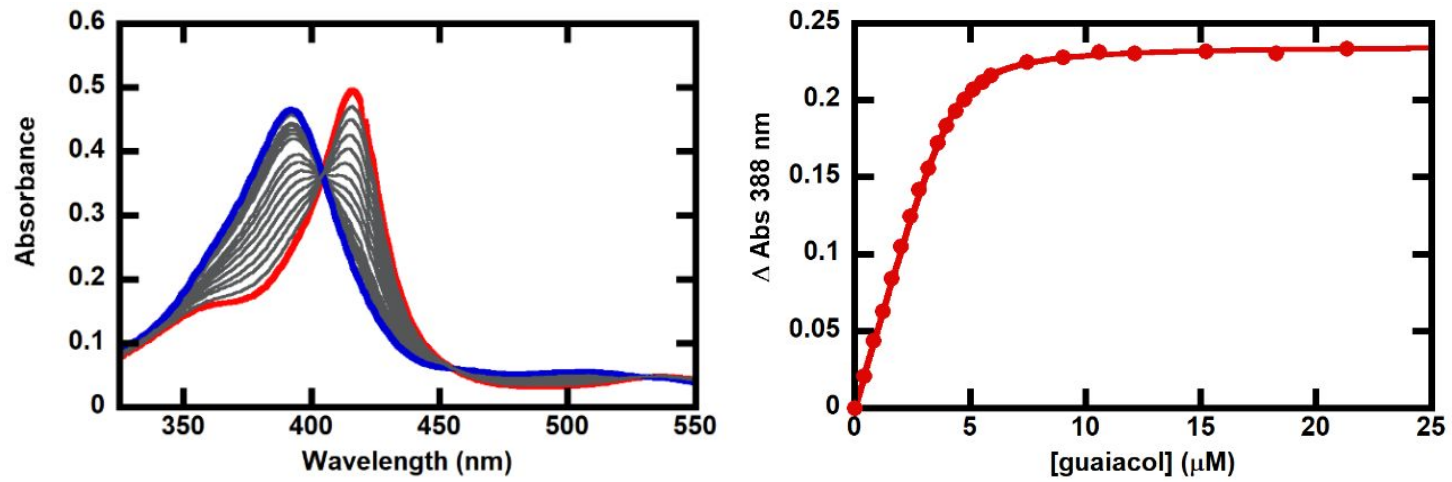

WT GcoA with o-vanillin $\left(K_{D}=28 \pm 4 \mu \mathrm{M}\right)$
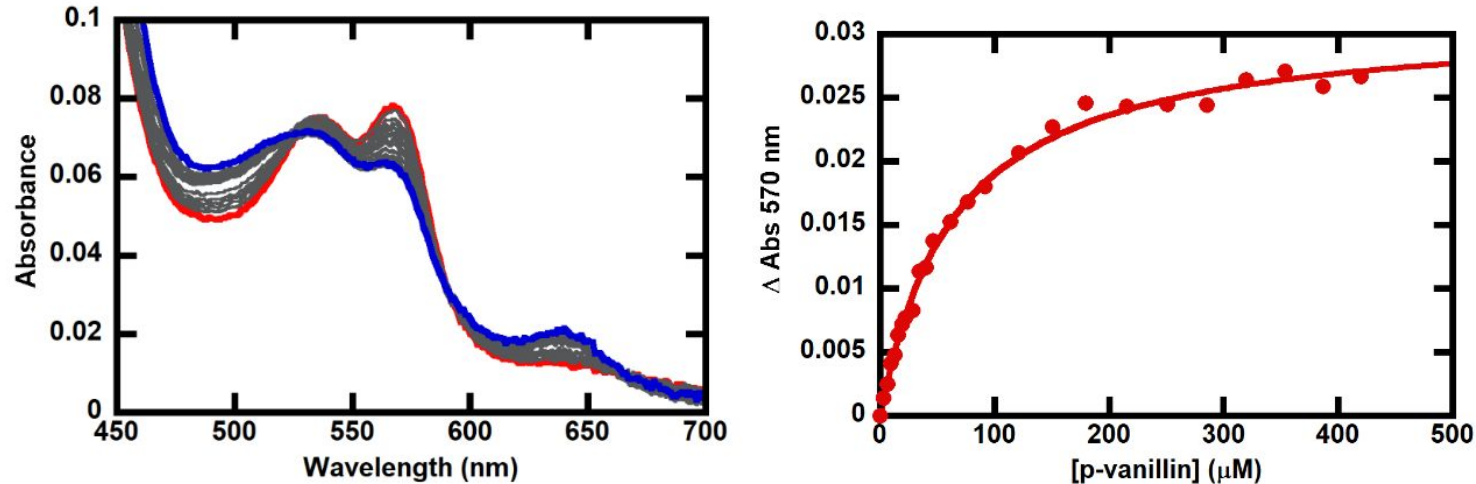

WT GcoA with p-vanillin $\left(K_{D}=60 \pm 4 \mu \mathrm{M}\right)$
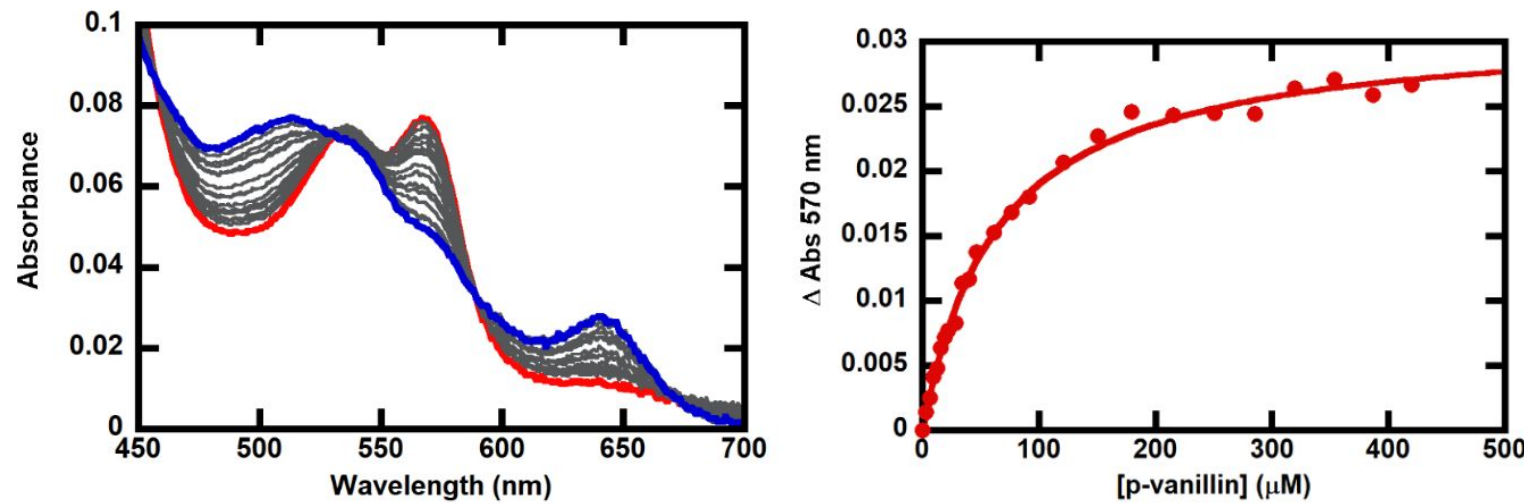
F169S GcoA with guaiacol $\left(K_{D}=19.1 \pm 0.3 \mu \mathrm{M}\right)$
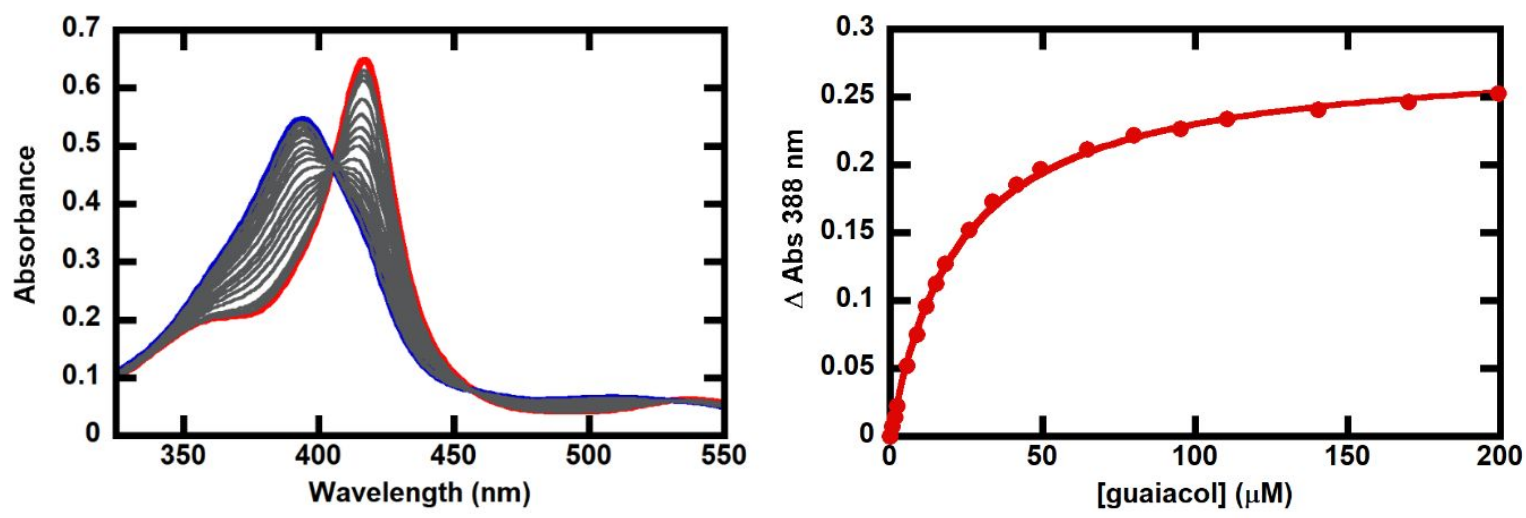

F169S GcoA with o-vanillin $\left(K_{D}=38 \pm 3 \mu M\right)$
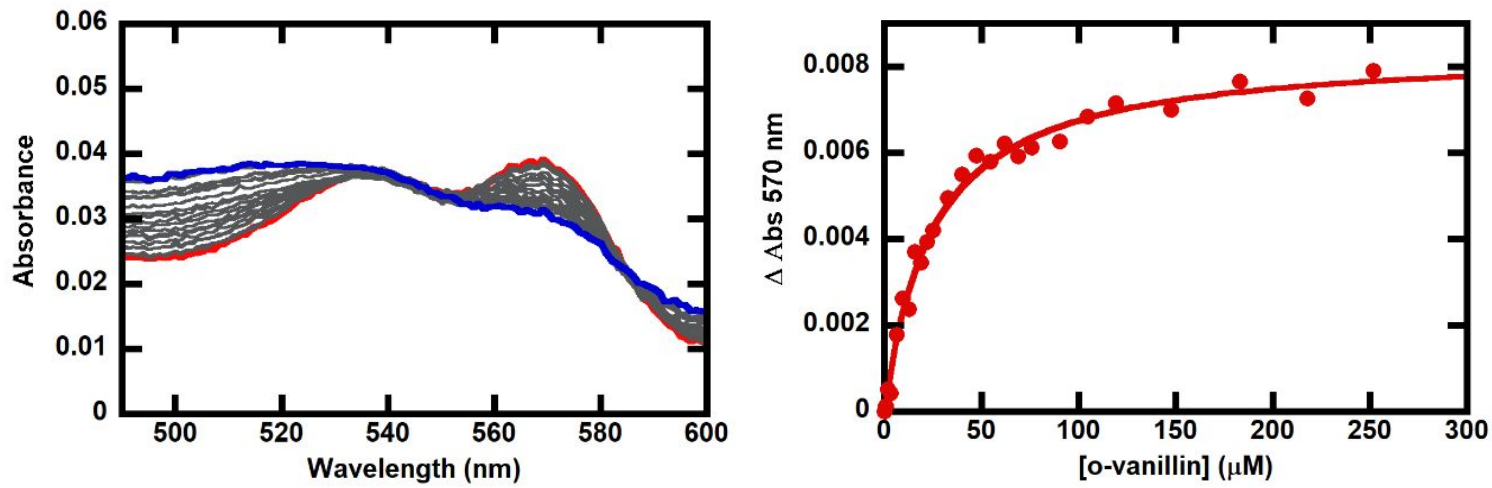

F169S GcoA with p-vanillin (No appreciable binding affinity)
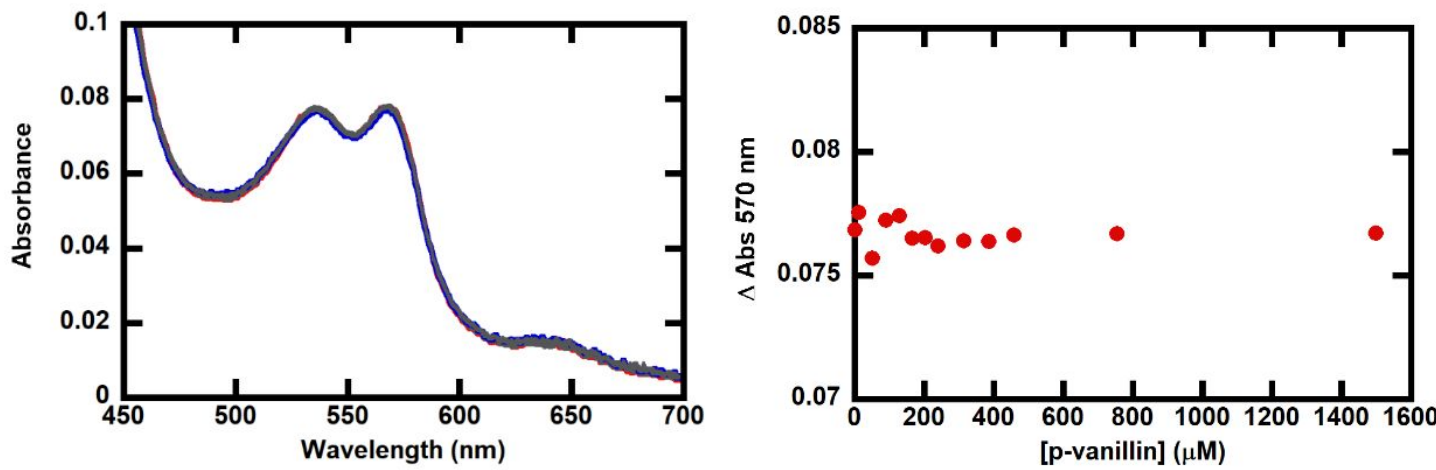

T296S GcoA with guaiacol $\left(K_{D}=4.1 \pm 0.1 \mu \mathrm{M}\right)$
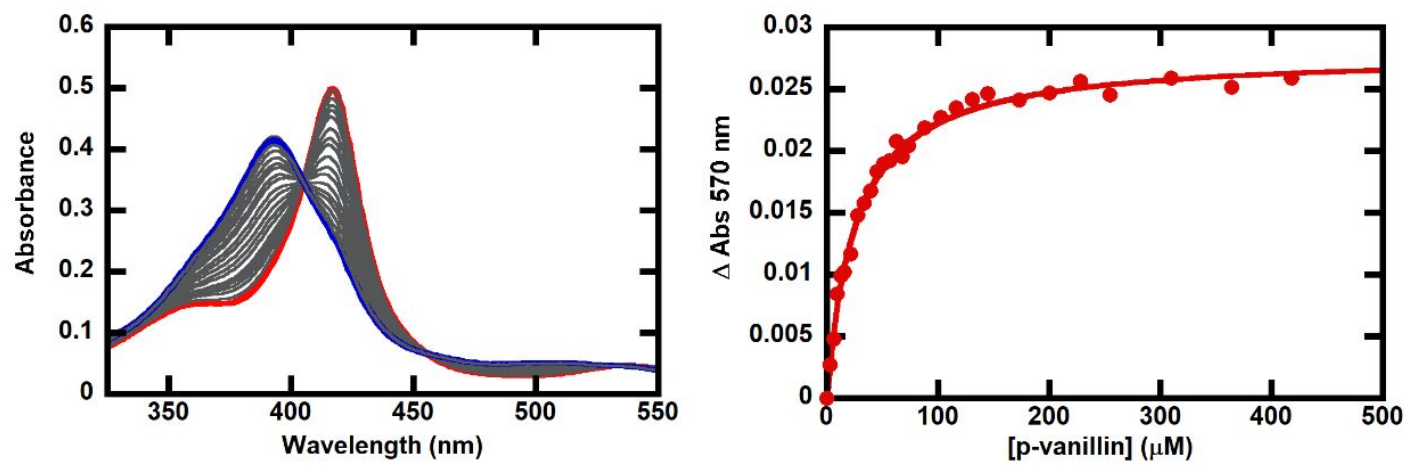
T296S GcoA with o-vanillin $\left(K_{D}=80 \pm 10 \mu M\right)$
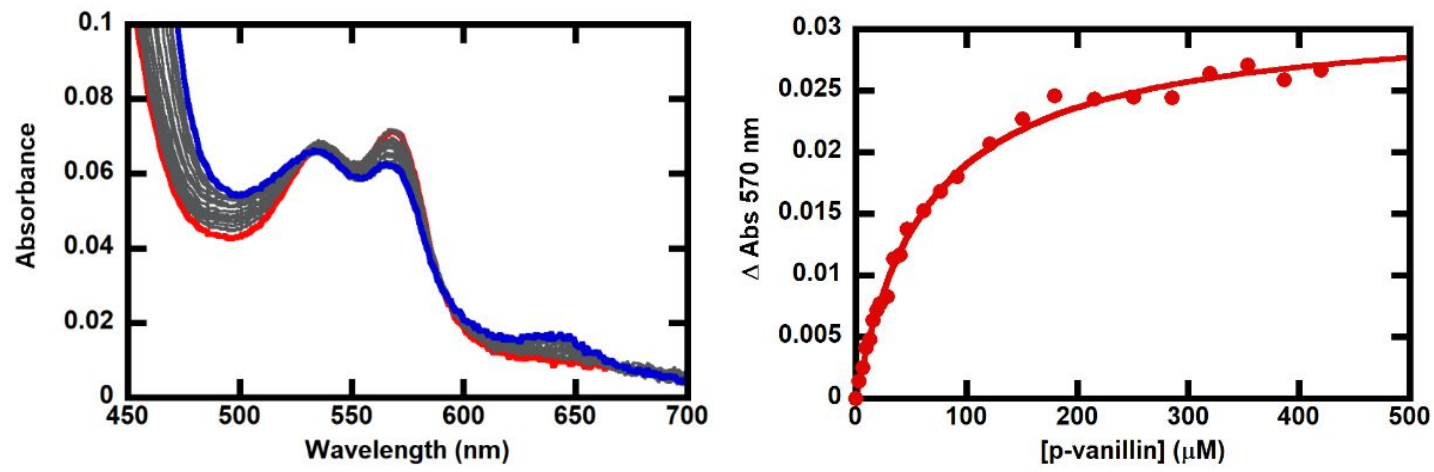

T296S GcoA with p-vanillin $\left(K_{D}=28 \pm 2 \mu \mathrm{M}\right)$
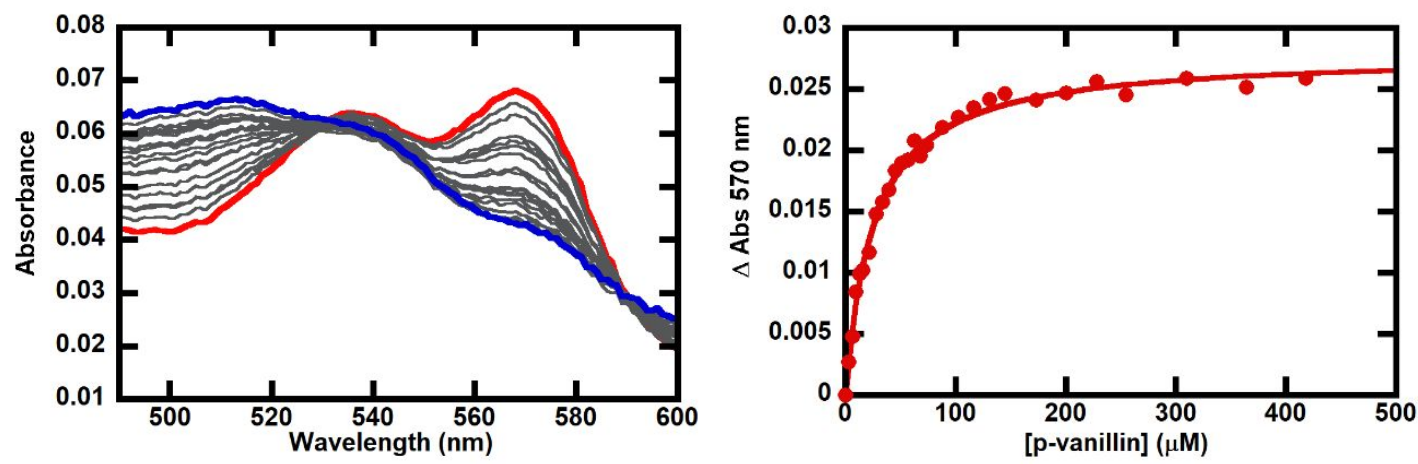

F169A/T296S GcoA with guaiacol $\left(\mathrm{K}_{\mathrm{D}}=155 \pm 4 \mu \mathrm{M}\right)$
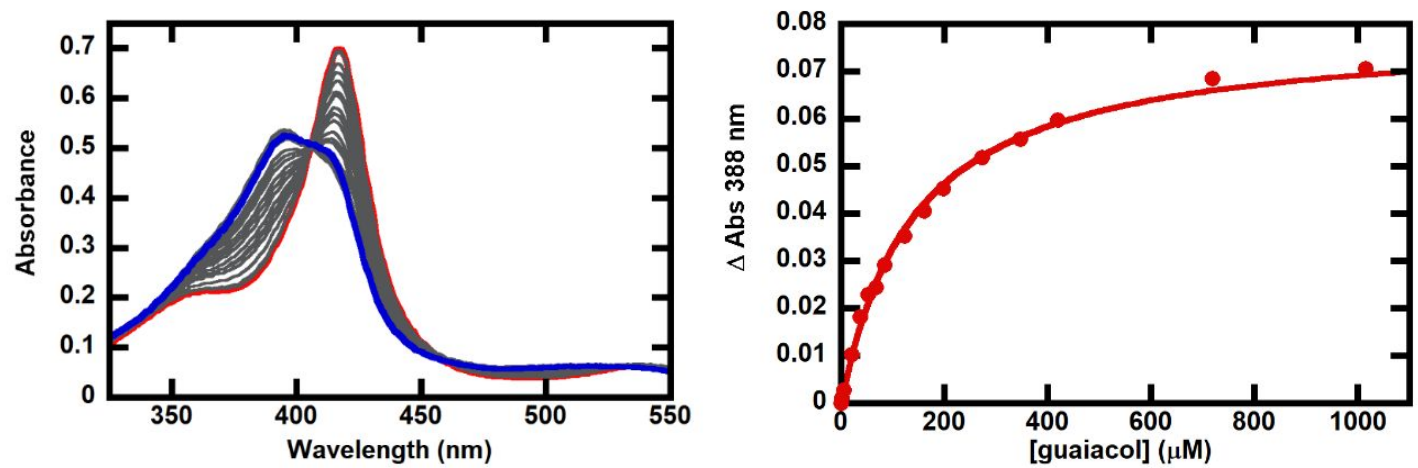

Figure S2. Spectroscopic changes reflecting conversion from high- to low-spin Fe(III) were used to measure the binding affinity $\left(K_{D}\right)$ of GcoA variants for guaiacol and vanillins. Measurement of binding affinities of WT, T296S, F169S, and F169A/T296S GcoA for guaiacol, $p$-vanillin, and o-vanillin was carried out by monitoring characteristic changes in the UV/vis spectrum of the enzyme upon substrate binding. A $600 \mu \mathrm{L}$ solution containing 5-10 $\mu \mathrm{M}$ of enzyme was titrated with small volumes $(1-5 \mu \mathrm{l})$ of ligand from a $0.250-10 \mathrm{mM}$ stock and the UV/Vis spectrum was measured after each addition of ligand. For each enzyme/substrate pair at least two titrations were carried out and the average results for each $\mathrm{K}_{\mathrm{d}}$ are reported in Table S1. Typical titrations for each combination are shown above (left) with the initial spectrum in red and the final spectrum, representing the substrate-saturated enzyme, in blue. The absorbance data was corrected for dilution and the change in absorbance at either $388 \mathrm{~nm}$ (guaiacol) or $570 \mathrm{~nm}$ (o- and $p$-vanillin) was plotted as a function of substrate (right) concentration and fit to Equation S1 or S2 (see SI Section 1). No measurable change in the UV/vis spectrum was observed for F169A/T296S GcoA in the presence of either added $o$-vanillin or $p$-vanillin (data not shown). 
Figure S3

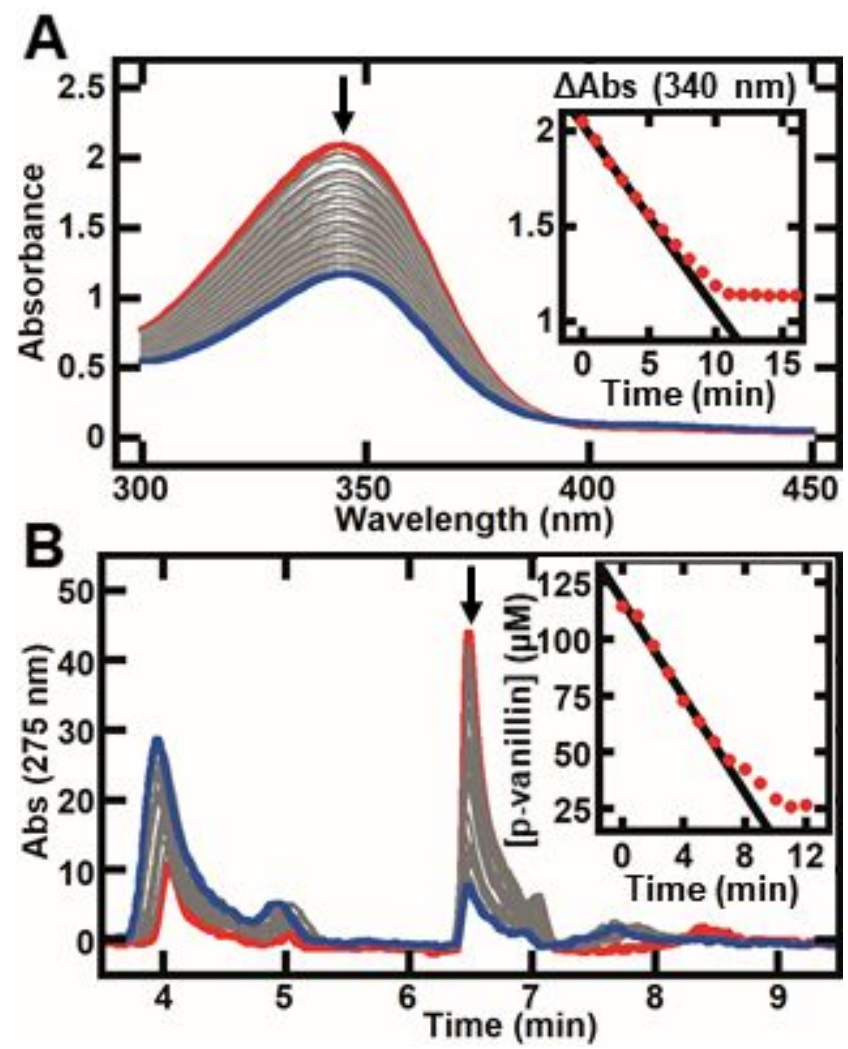

Figure S3. Representative measurements of substrate consumption in the oxidation of guaiacol or $p$ vanillin by GcoA-T296S. These data illustrate the raw data used to generate the bar chart shown in the main text (Figure 2). (A) For endpoint assays to determine the percent-coupling of NADH consumption to formaldehyde production and substrate demethylation, consumption of NADH over time was monitored by UV/Vis absorbance spectroscopy for 45 minutes or until there was no further change observed in the absorbance spectrum. The reaction was then quenched with concentrated $\mathrm{H}_{2} \mathrm{SO}_{4}$, and the change in absorbance at $340 \mathrm{~nm}$ was used to determine the amount of NADH consumed. For each combination of substrate and GcoA variant, a single reaction mixture containing $0.2-0.5 \mu \mathrm{M} \mathrm{GcoAB}, 100 \mu \mathrm{g} / \mathrm{ml}$ catalase, and $250 \mu \mathrm{M}$ NADH was prepared and initiated with $250 \mu \mathrm{M}$ (guaiacol, o-vanillin) or $100 \mu \mathrm{M}$ ( $p$-vanillin). The reaction shown is demethylation of guaiacol by GcoA-T296S. Inset: Initial rate plots of NADH consumption at $\lambda_{\max }=340 \mathrm{~nm}$ were generated to determine specific activity. (B) Substrate consumption was quantified using an Agilent 1100 LC system equipped with a G1315A diode array detector (DAD). Each sample and standard was injected at a volume of $25 \mu \mathrm{L}$ onto a Waters $\mathrm{C} 18$ column $\left(4.6 \times 150 \mathrm{~mm}, 5 \mu \mathrm{m}\right.$ particle diameter) maintained at $37^{\circ} \mathrm{C}$. The mobile phase used to separate the analytes of interest was water (A)/acetonitrile (B), each with $0.1 \%$ trifluoroacetic acid. The separation was carried out using a flow rate of $1.5 \mathrm{ml} / \mathrm{min}$, with the following program: 0-2 min, $5 \% \mathrm{~B}$ (isocratic); $2-8 \mathrm{~min}, 5$ to $50 \%$ B (gradient); 8-11 min, 95\% B (isocratic); 11-13 min, 5\% B (isocratic). A DAD wavelength of $275 \mathrm{~nm}$ was used for analysis of the analytes of interest. A minimum of 3-5 calibration levels was used with an $r^{2}$ coefficient of 0.99 or better for each analyte. The reaction shown is demethylation of $p$-vanillin by GcoA-T296S. 
Figure S4

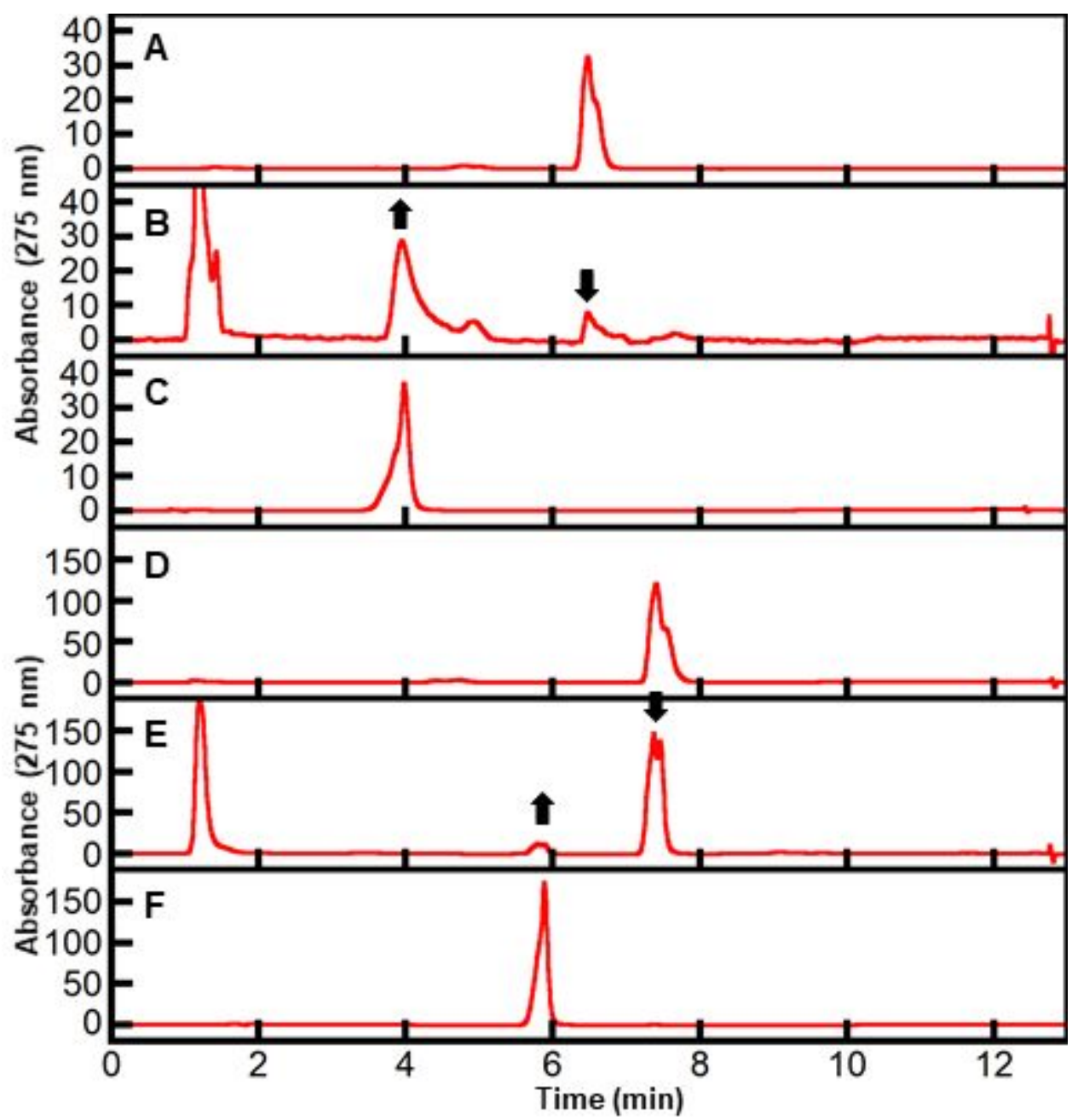

Figure S4. Consumption of the aromatic substrates was quantified using HPLC: (A) p-vanillin (6.5 min), (B) representative trace from a $p$-vanillin consumption assay using GcoA-T296S with arrows indicating substrate and product peaks, (C) 3,4-dihydroxybenzaldehyde standard (4.0 $\mathrm{min}$ ), (D) o-vanillin (7.4 $\mathrm{min}$ ), (E) representative trace from an o-vanillin consumption assay using GcoA-F169V with arrows indicating substrate and product peaks, and (F) 2,3-dihydroxybenzaldehyde standard (5.9 min). The mobile phase used to separate the analytes of interest was water $(A) /$ acetonitrile $(B)$, each with $0.1 \%$ trifluoroacetic acid. The separation was carried out using a flow rate of $1.5 \mathrm{ml} / \mathrm{min}$, with the following program: $0-2 \mathrm{~min}, 5 \% \mathrm{~B}$ (isocratic); 2-8 min, 5 to $50 \%$ B (gradient); 8-11 min, 95\% B (isocratic); $11-13$ min, $5 \%$ B (isocratic). A DAD wavelength of $275 \mathrm{~nm}$ was used for analysis of the analytes of interest.

[[page break here $\rightarrow]$ ] 
Figure S5

WT GcoA with guaiacol $\left(\mathrm{K}_{\mathrm{M}}=0.037 \pm 0.008 \mathrm{mM}, \mathrm{k}_{\text {cat }}=0.57 \pm 0.03 \mathrm{~s}^{-1}, \mathrm{~K}_{\mathrm{M}} / \mathrm{k}_{\text {cat }}=15 \pm 3 \mathrm{mM}^{-1} \mathrm{~s}^{-1}\right)$

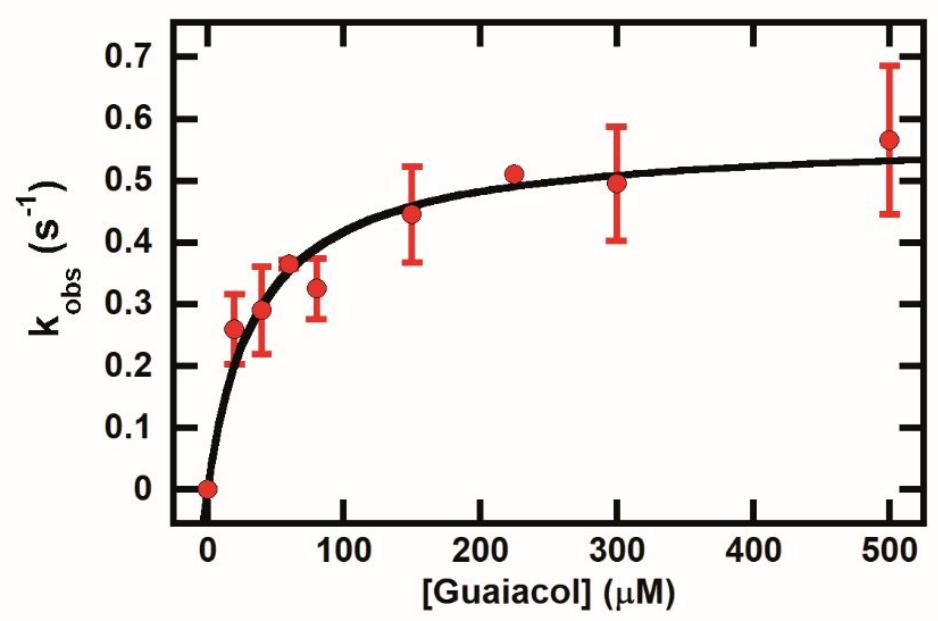

WT GcoA with o-vanillin $\left(\mathrm{K}_{\mathrm{M}}=0.54 \pm 0.2 \mathrm{mM}, \mathrm{k}_{\text {cat }}=0.36 \pm 0.09 \mathrm{~s}^{-1}, \mathrm{~K}_{\mathrm{M}} / \mathrm{K}_{\text {cat }}=0.7 \pm 0.3 \mathrm{mM}^{-1} \mathrm{~s}^{-1}\right)$

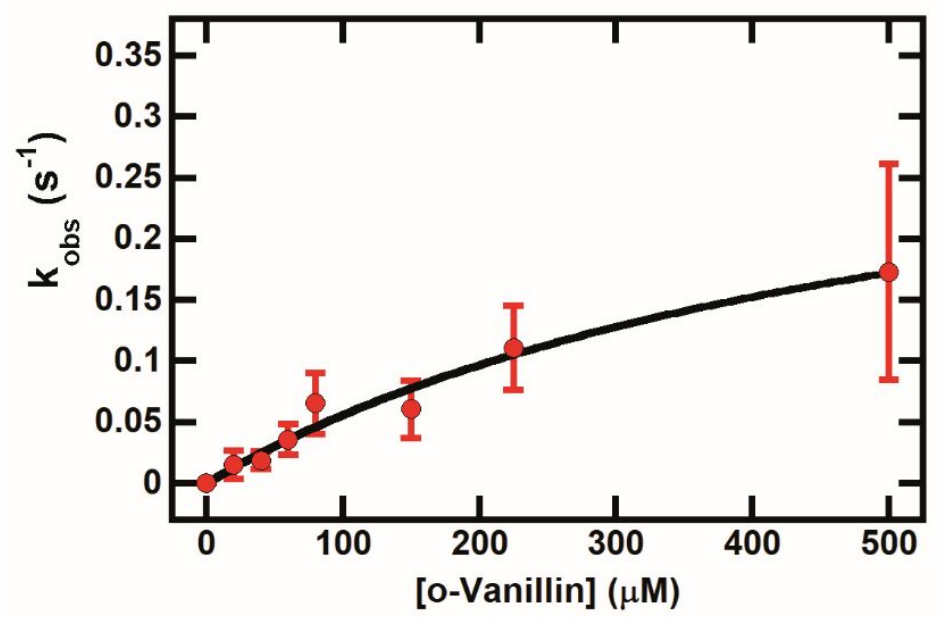

WT GcoA with p-vanillin $\left(\mathrm{K}_{\mathrm{M}}=0.27 \pm 0.08 \mathrm{mM}, \mathrm{k}_{\text {cat }}=0.50 \pm 0.08 \mathrm{~s}^{-1}, \mathrm{~K}_{\mathrm{M}} / \mathrm{K}_{\text {cat }}=1.9 \pm 0.7 \mathrm{mM}^{-1} \mathrm{~s}^{-1}\right)$

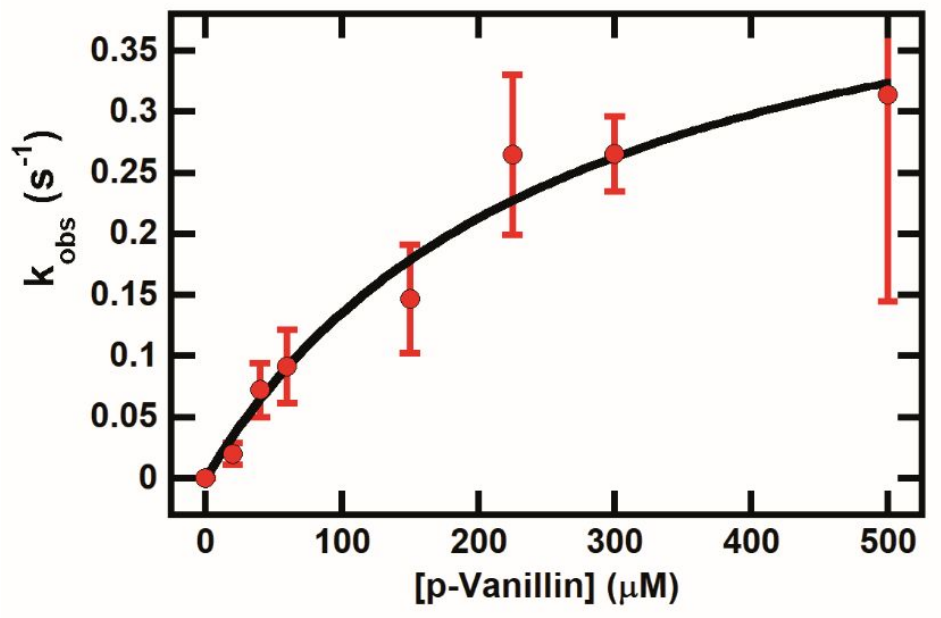


F169S GcoA with guaiacol $\left(\mathrm{K}_{\mathrm{M}}=0.07 \pm 0.02 \mathrm{mM}, \mathrm{k}_{\text {cat }}=0.40 \pm 0.04 \mathrm{~s}^{-1}, \mathrm{~K}_{\mathrm{M}} / \mathrm{k}_{\text {cat }}=5.7 \pm 1.7 \mathrm{mM}^{-1} \mathrm{~s}^{-1}\right)$

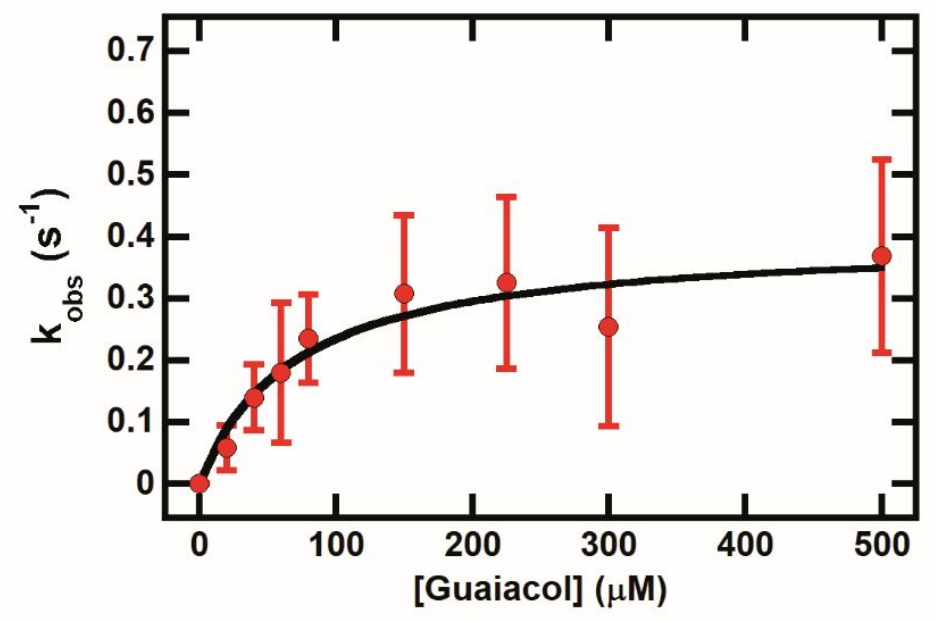

F169S GcoA with o-vanillin $\left(\mathrm{K}_{\mathrm{M}}=0.12 \pm 0.04 \mathrm{mM}, \mathrm{k}_{\text {cat }}=0.37 \pm 0.05 \mathrm{~s}^{-1}, \mathrm{~K}_{\mathrm{M}} / \mathrm{k}_{\text {cat }}=3.1 \pm 1.1 \mathrm{mM}^{-1} \mathrm{~s}^{-1}\right)$

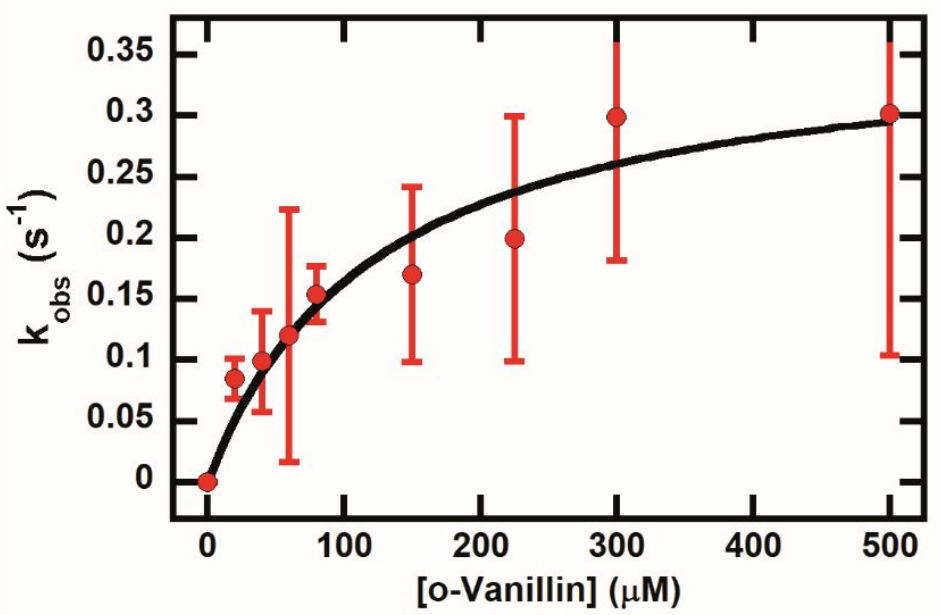

T296S GcoA with guaiacol $\left(\mathrm{K}_{\mathrm{M}}=0.08 \pm 0.02 \mathrm{mM}, \mathrm{k}_{\text {cat }}=0.63 \pm 0.07 \mathrm{~s}^{-1}, \mathrm{~K}_{\mathrm{M}} / \mathrm{k}_{\text {cat }}=8 \pm 3 \mathrm{mM}^{-1} \mathrm{~s}^{-1}\right)$

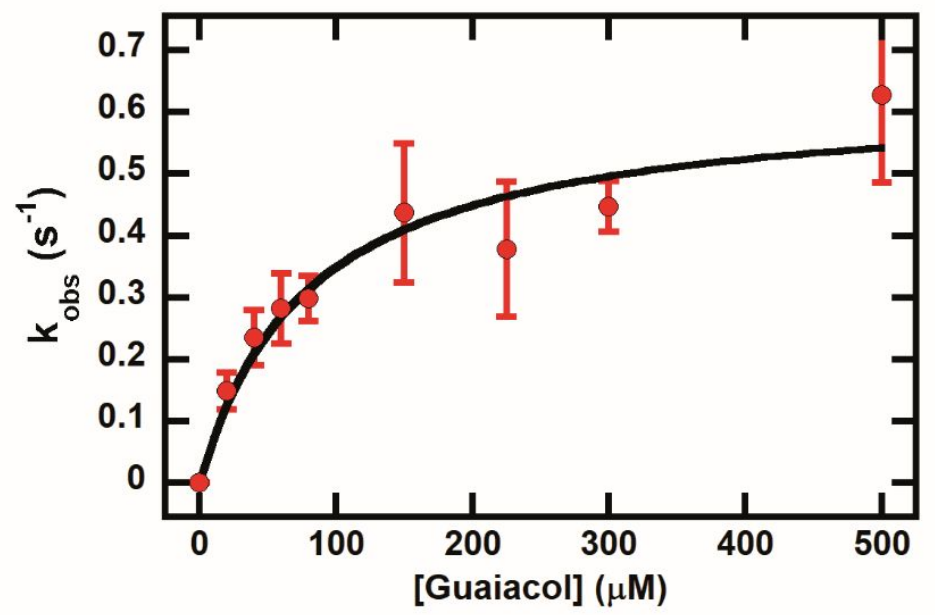


T296S GcoA with p-vanillin $\left(\mathrm{K}_{\mathrm{M}}=0.05 \pm 0.02 \mathrm{mM}, \mathrm{k}_{\text {cat }}=0.63 \pm 0.08 \mathrm{~s}^{-1}, \mathrm{~K}_{\mathrm{M}} / \mathrm{k}_{\text {cat }}=13 \pm 5 \mathrm{mM}^{-1} \mathrm{~s}^{-1}\right)$

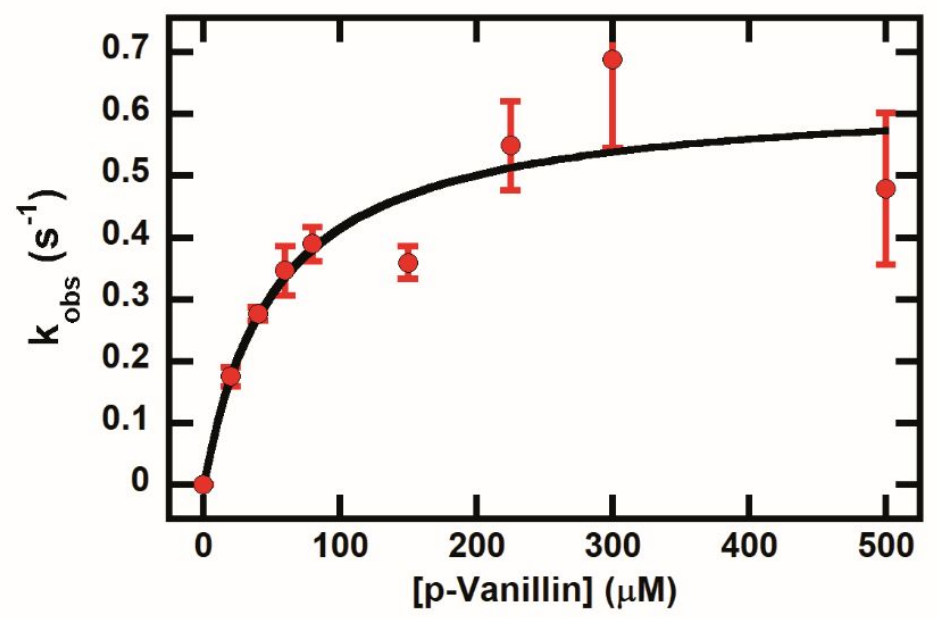

Figure S5. Representative Michaelis Menten plots. The steady state kinetics for demethylation of guaiacol, $p$ vanillin, and $o$-vanillin by GcoA variants were measured by monitoring the consumption of substrate discontinuously by HPLC (see SI Section 1 and Figures S3-S4). In the presence of $100 \mu \mathrm{g} / \mathrm{ml}$ catalase, $0.5 \mu \mathrm{M}$ GcoAB was incubated with $20-500 \mu \mathrm{M}$ substrate in room temperature, air-saturated buffer $(25 \mathrm{mM} \mathrm{HEPES}, 100 \mathrm{mM} \mathrm{NaCl}, \mathrm{pH}$ 7.5; up to $210 \mu \mathrm{M} \mathrm{O}_{2}$ ). After the reaction was initiated by addition of $300 \mu \mathrm{M} \mathrm{NADH}$, a $50 \mu \mathrm{L}$ sample was removed every $30 \mathrm{~s}$ for $2 \mathrm{~min}$. For each reaction, a $50 \mu \mathrm{L}$ sample was taken from a duplicate reaction mixture containing no GcoAB to give a " $0 \mathrm{~s}$ " timepoint. Each sample was quenched with $\mathrm{H}_{2} \mathrm{SO}_{4}$ immediately, and then stored at $4{ }^{\circ} \mathrm{C}$ in the HPLC autosampler unit. A progress of reaction curve was generated for each reaction and fit to a line equation to determine the initial rate of substrate consumption relative to the concentration of $G \operatorname{coAB}\left(\mathrm{v}_{\mathrm{i}} /[\mathrm{E}]\right)$. Each reaction was performed at least in triplicate and the results averaged. Rate plots were fit to Equation S3. The Michaelis constants are apparent, as the dioxygen and GcoB concentrations are not known to be saturating. 
Figure S6

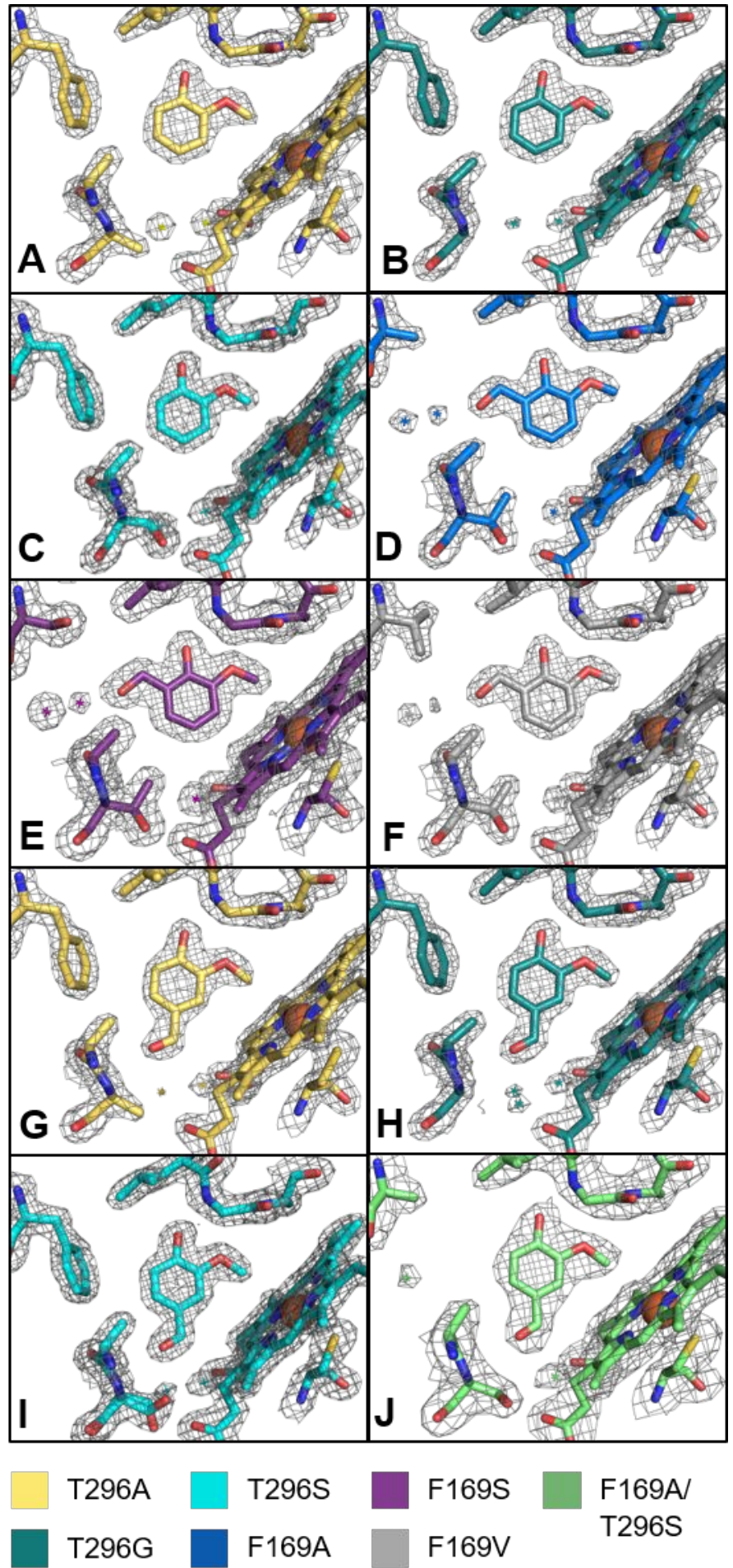

Figure S6. Electron density of GcoA ligand-bound active sites. Panels (A) - (C) show the structures of guaiacol bound to GcoA-T296A, G and $S$ respectively. Panels $(D)-(E)$ show the structures of $o$-vanillin bound to GcoA-F169A, S and V. Panels (G) - (J) show the structures of p-vanillin bound to GcoA-T296A, G, S and GcoAF169A_T296S respectively. All $2 F_{0}-F_{c}$ maps are contoured at 2 sigma for comparison. 
Figure S7

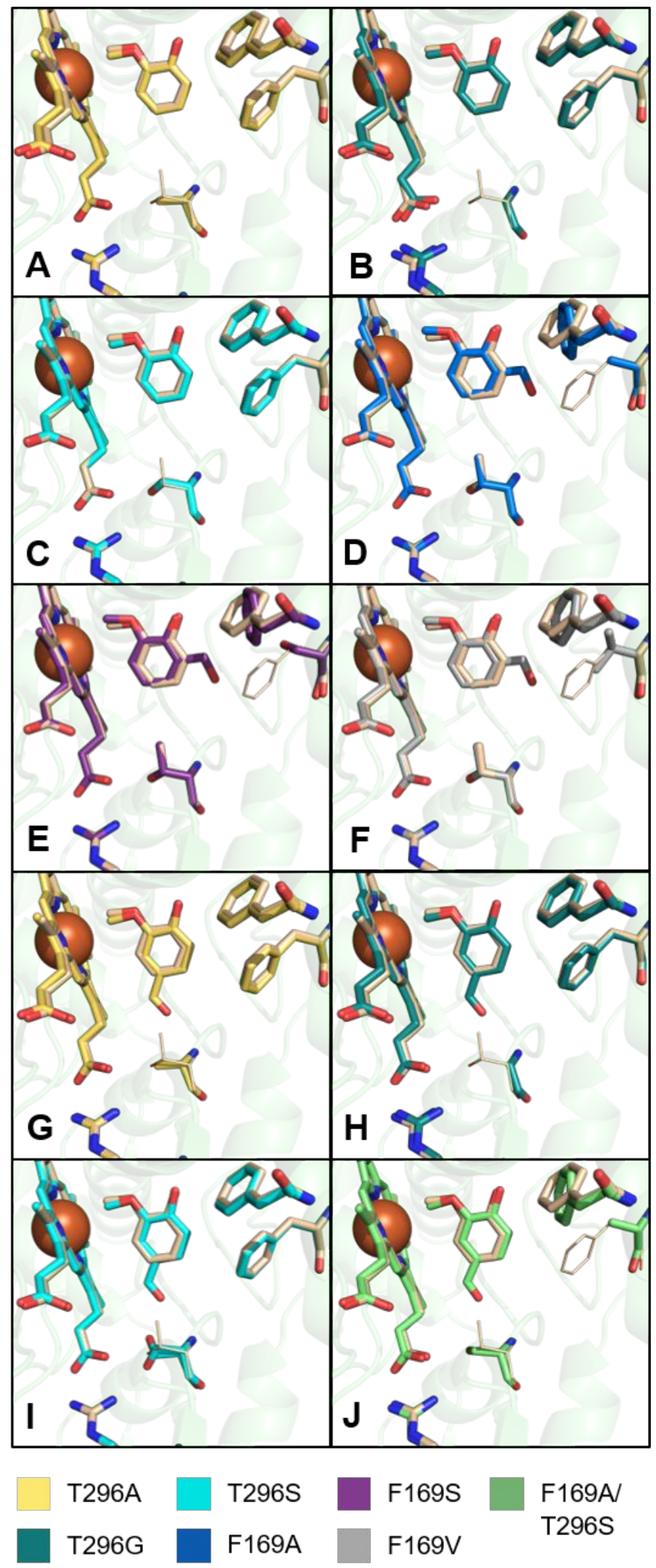

Figure S7. Ligand binding comparisons to preferred wildtype substrate guaiacol. Panels $(A)-(C)$ show the structures of guaiacol bound to GcoA-T296A, $G$ and $S$ respectively. Panels $(D)-(E)$ show the structures of ovanillin bound to GcoA-F169A, S and V. Panels $(G)-(J)$ show the structures of $p$-vanillin bound to GcoA-T296A, G, S and GcoA-F169A_T296S respectively all superimposed with wildtype guaiacol (5NCB). 
Figure S8

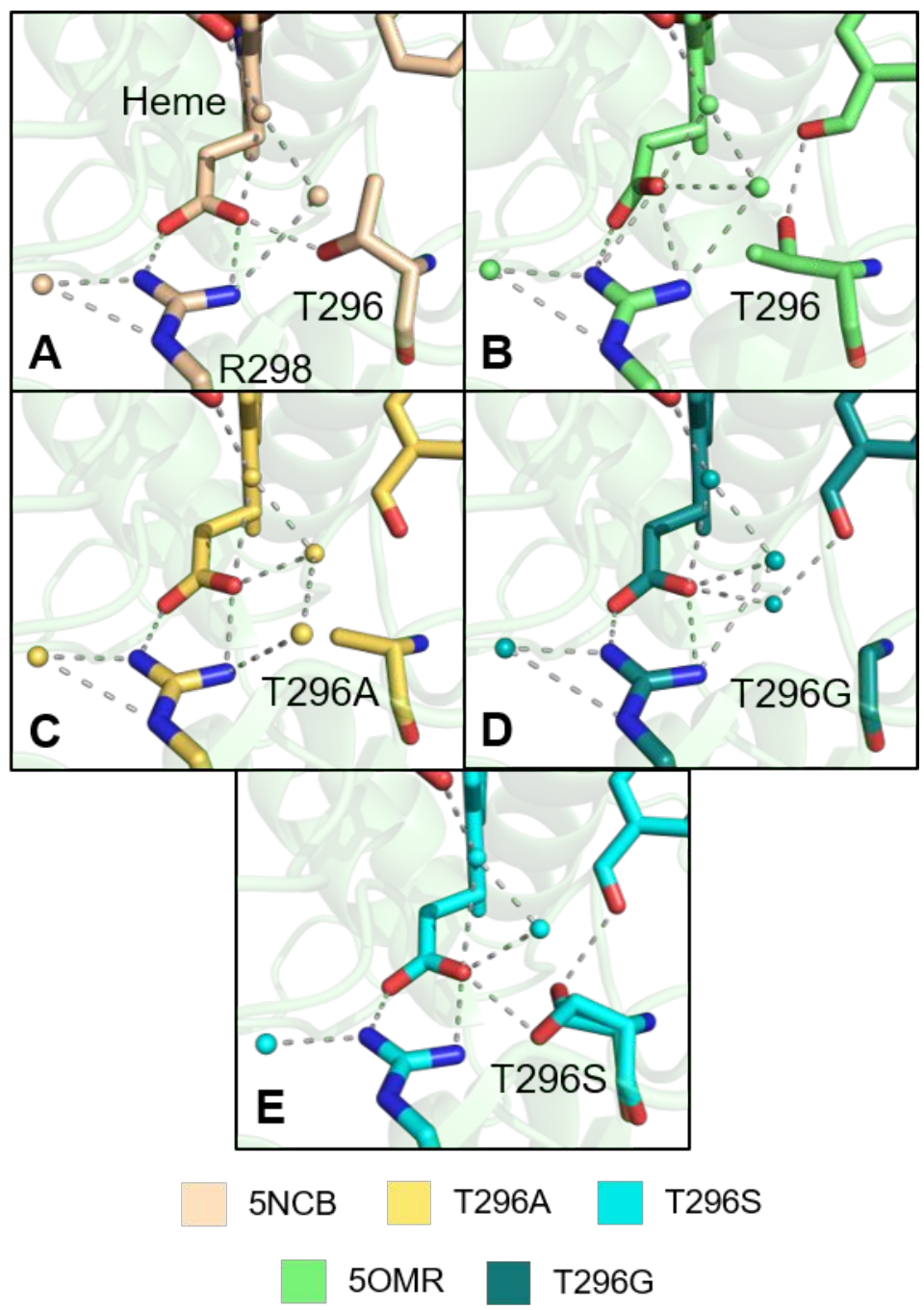

Figure S8. Hydrogen bond network around heme propionate. Panel $(A)$ shows the structure of guaiacol bound to GcoA $(5 N C B)$, focusing on the hydrogen bond network around the heme propionate. Panel $(B)-(E)$ shows the structures of $p$-vanillin bound to GcoA-WT (5OMR), T296A, G, and S respectively. 
Figure S9

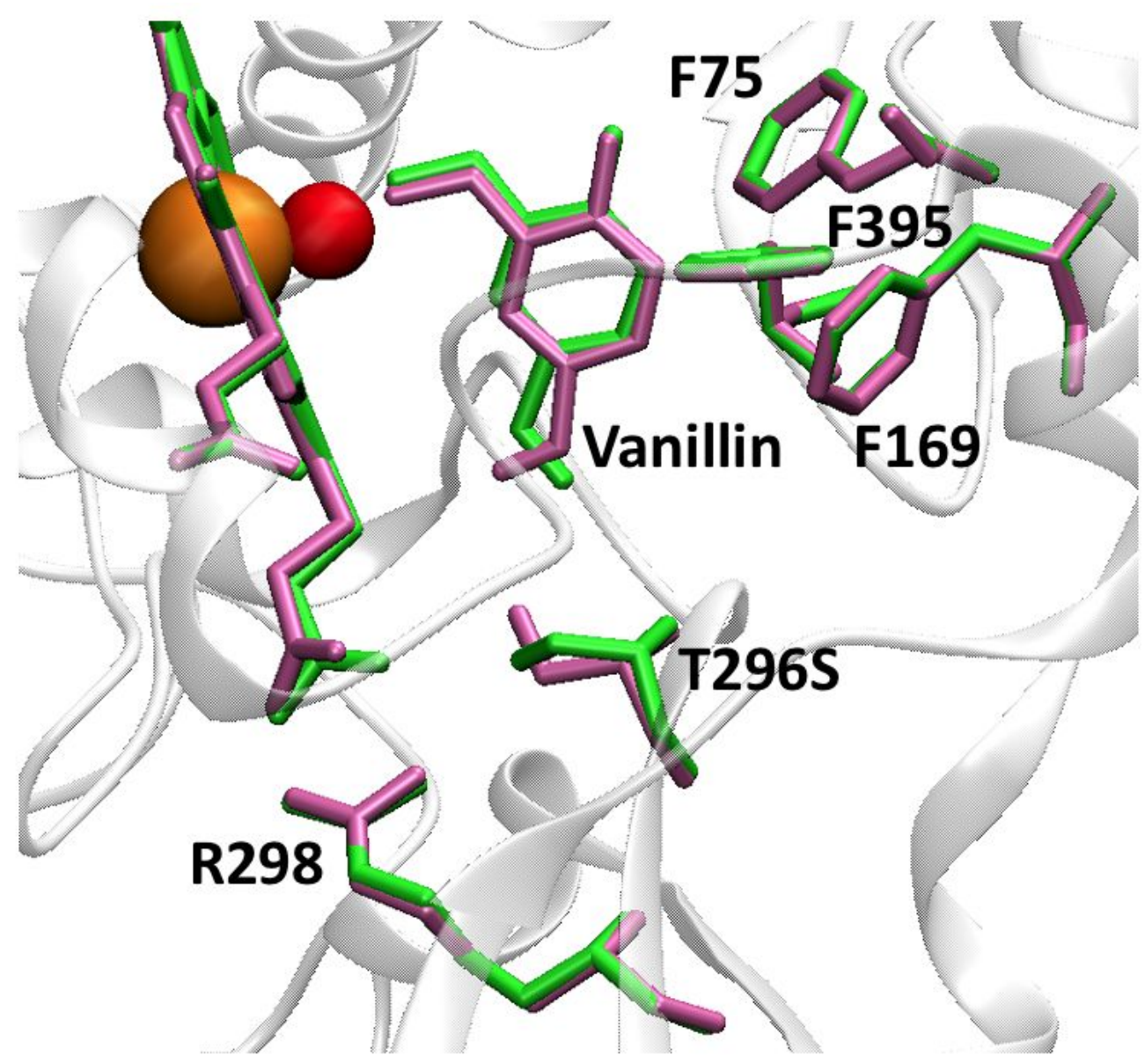

Figure S9. Starting configuration for T296S molecular dynamics (MD) simulation with bound $p$-vanillin. Comparison of the ligand binding mode in the crystal structure of T296S mutant (PDB code 6CYM, green) and the initial structure used in the MD simulation (pink), where threonine was mutated to serine manually from the structure of WT GcoA with p-vanillin bound (5OMR); the 6CYM crystal structure was not yet available at the time the simulations were initiated. Overall, the configurations are very similar, differing primarily in the orientation of the aldehyde group in vanillin and the hydroxyl group in T296S. In the subsequent simulations, the aldehyde group rotated within the first $1 \mathrm{~ns}$ to adopt and remain in the conformation exhibited in the crystal structure. 


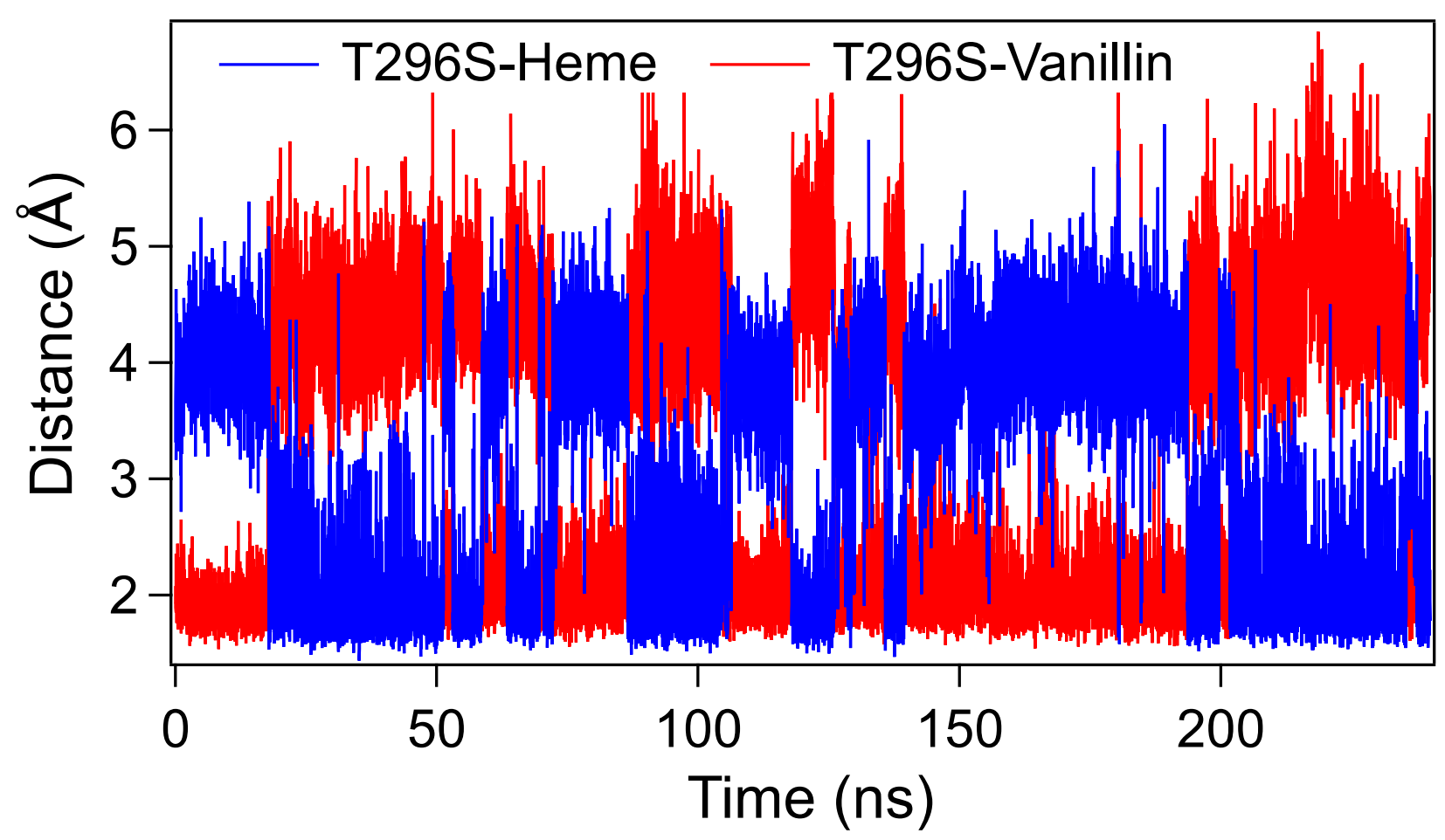

Figure S10. Dynamic evolution of hydrogen bond partners in T296S GcoA with vanillin via molecular dynamics simulation. Over the course of 240 ns MD simulation, the hydrogen bond partner changes nearly twenty times for S296 between the aldehyde group of vanillin and the nearer heme propionate arm. The distance measured is from the serine hydrogen to the oxygen atom on either the aldehyde or the heme propionate. 
Figure S11
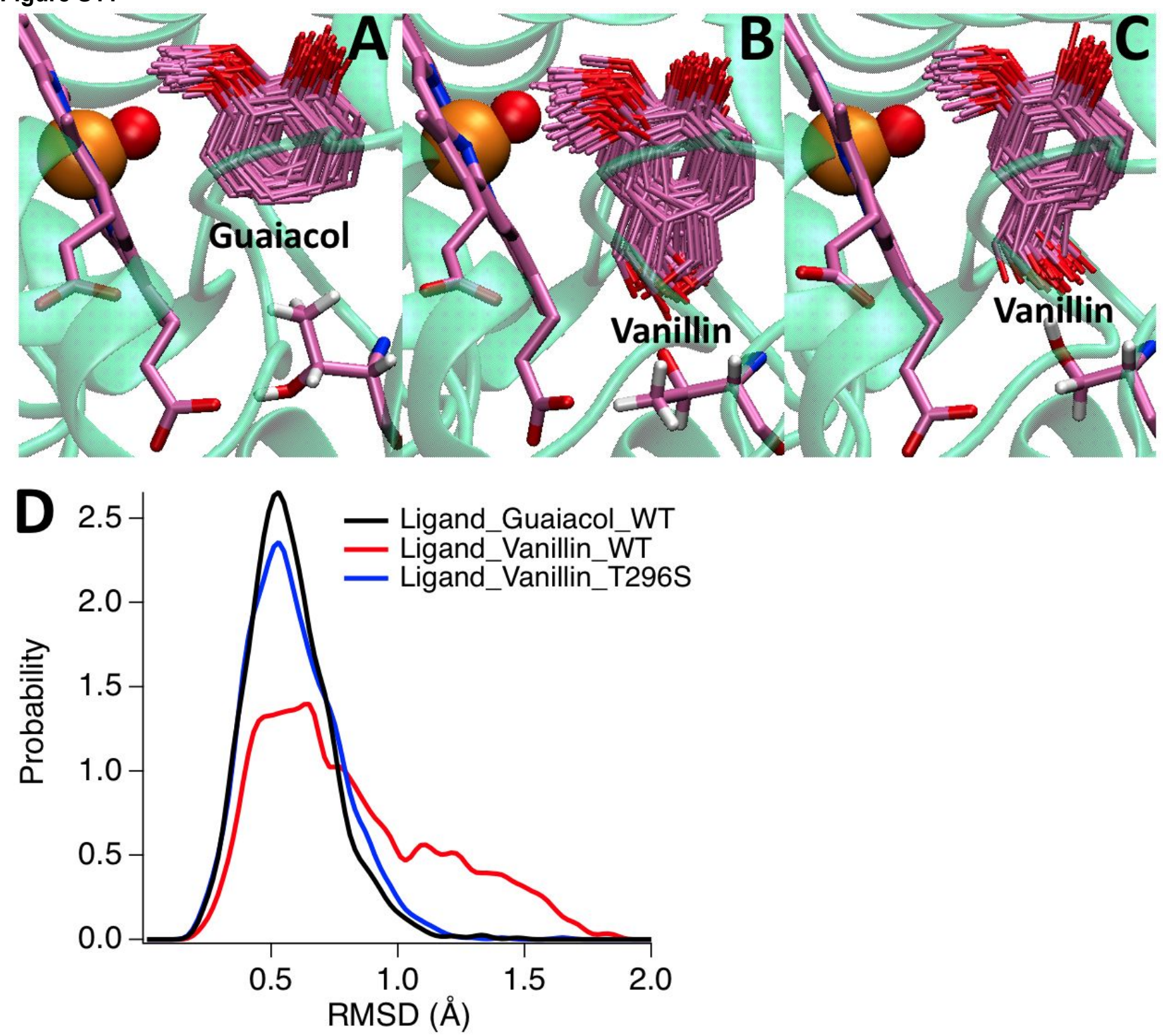

Figure S11. Binding mode of ligand in molecular dynamics simulations. (A) WT/guaiacol, (B) WT/vanillin, and (C) T296S/vanillin. The position of ligand is shown every 2 ns over the 240 ns MD simulations. (D) Probability distributions for the root mean square deviation (RMSD) of the six ring carbons of ligand relative to their positions in the crystal structure of WT GcoA/guaiacol (PDB ID 5NCB). 

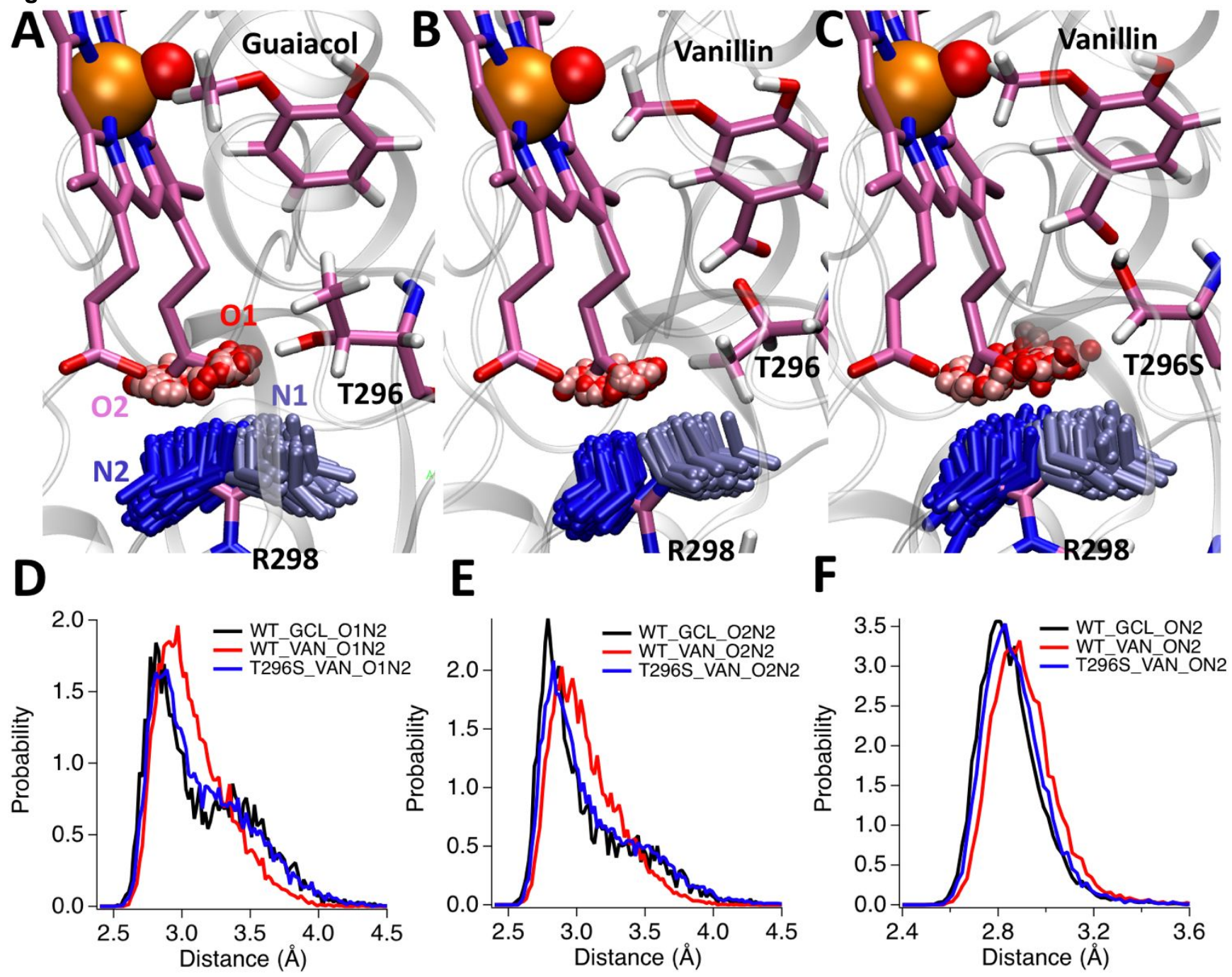

Figure S12. R298 interactions with heme propionate in molecular dynamics simulations. (A) WT/guaiacol, (B) WT/vanillin, and (C) T296S/vanillin. The positions of the two $-\mathrm{NH}_{2}$ groups in R298 and the two O atoms in the heme propionate arm nearer to residue 296 are shown every $2 \mathrm{~ns}$ over the $240 \mathrm{~ns}$ MD simulations. The probability distribution of the distance between N2 and $\mathrm{O} 1$ (D), N2 and O2 (E), the shortest distance between N2 and O1/O2 $(F)$. Note the restoration of the hydrogen bond network for T296S/vanillin as compared to WT/guaiacol. (N1: iceblue, N2: blue, O1: red, O2: pink). 


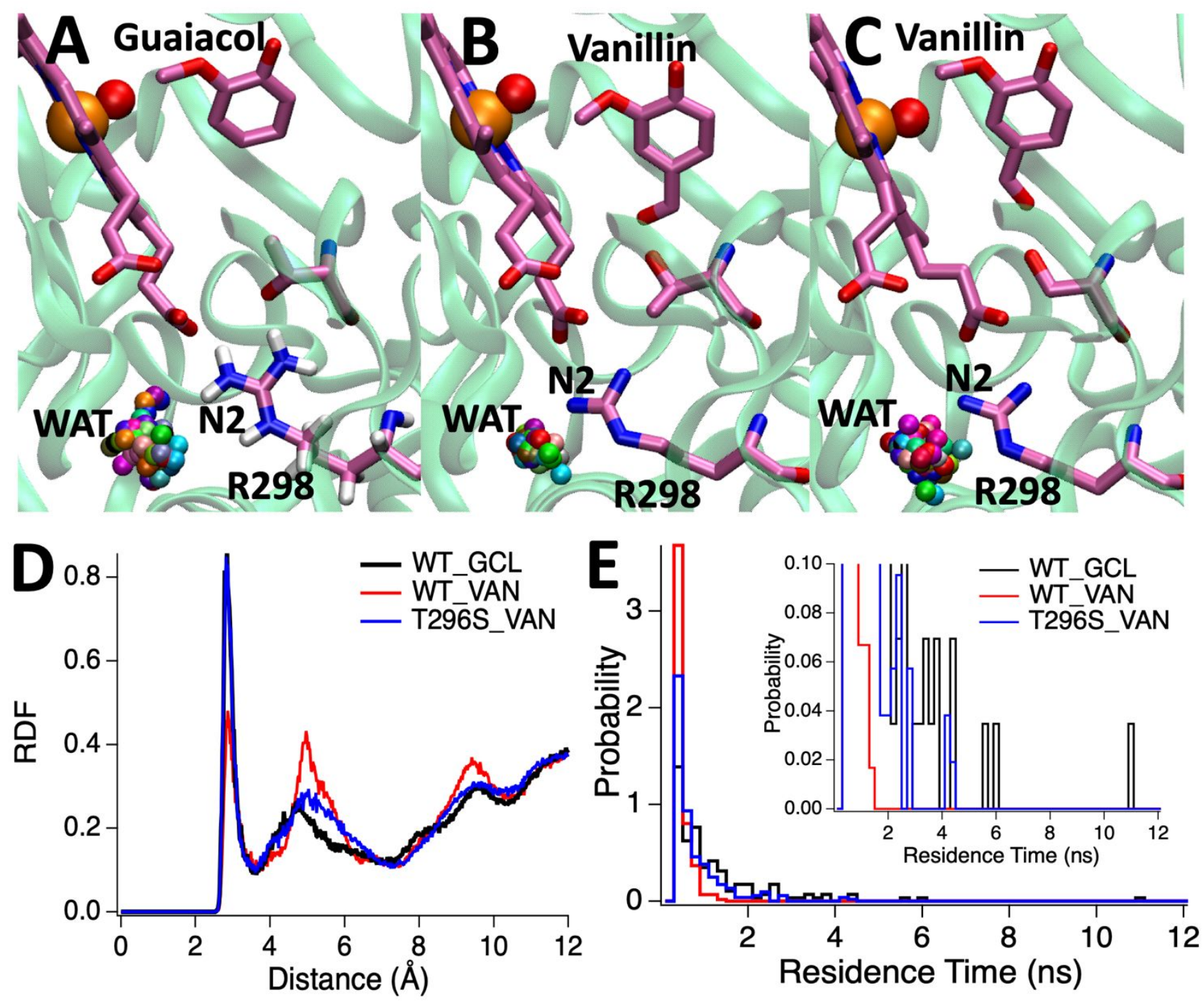

Figure S13. Active site water structure and dynamics from molecular dynamics simulations. Water positioning in MD for (A) WT/guaiacol, (B) WT/vanillin, and (C) T296S/vanillin. The positions of oxygen atoms in water molecules within a distance cutoff of $3.0 \AA$ from the N2 atom in R298 are shown every 2 ns over the 240 ns MD simulation. These water oxygen atoms are colored by residue ID. (D) The probability distribution of the distance between water oxygen and N2 atom in R298. (E) The probability distribution of residence time of water molecules within a distance cutoff of $3.0 \AA$ from the N2 atom in R298. Compared to the WT, long-lived water molecules in this vicinity are partially (but not fully) restored in the T296S case with vanillin bound. 
Figure S14

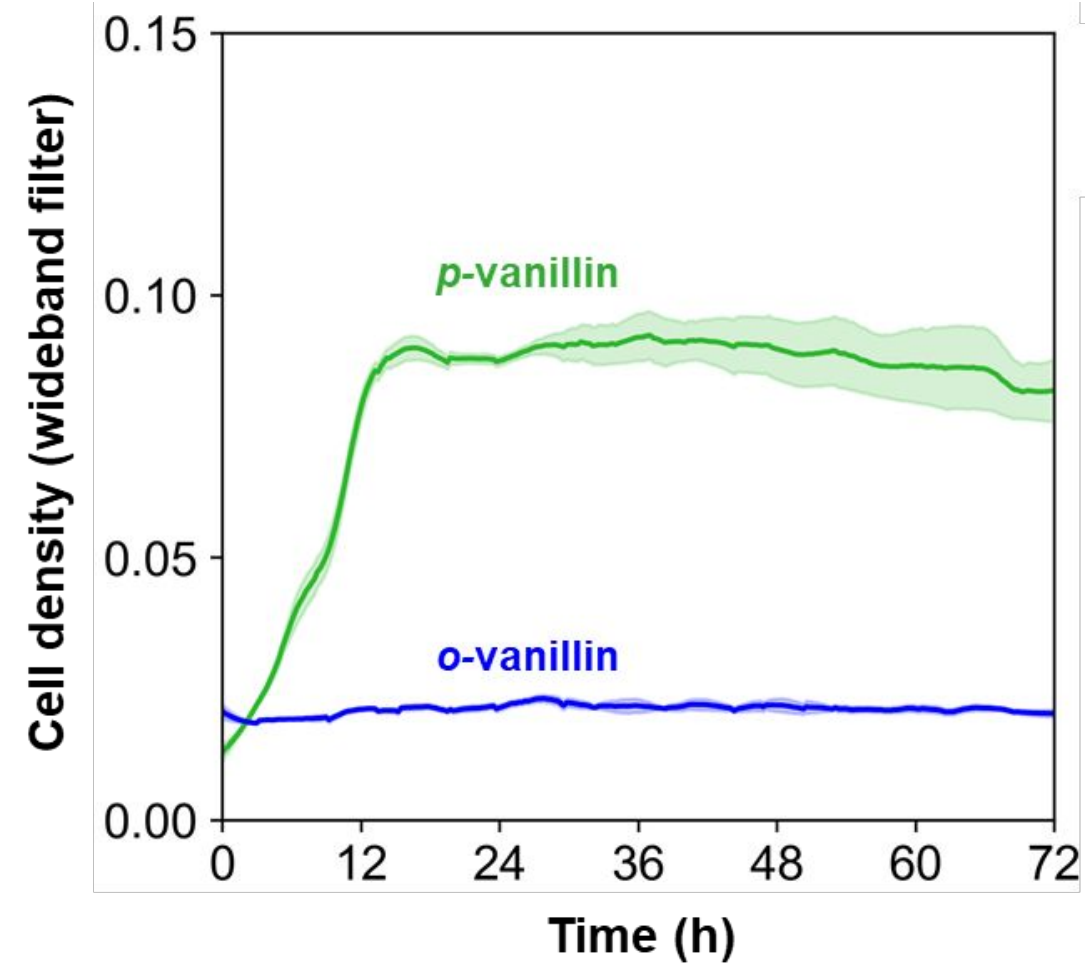

Figure S14. Growth curves for $P$. putida KT2440 wild-type on vanillin isomers. Cultures were grown in triplicate in microtiter plates in a Bioscreen C MBR (Oy Growth Curves Ab Ltd., Helsinki, Finland) with $5 \mathrm{mM}$ of either $p$-vanillin (green) or $o$-vanillin (blue). Error bars indicate the standard deviation from the mean of three replicates, and absorbance measurements are corrected by cell-free media blanks. 
Figure S15
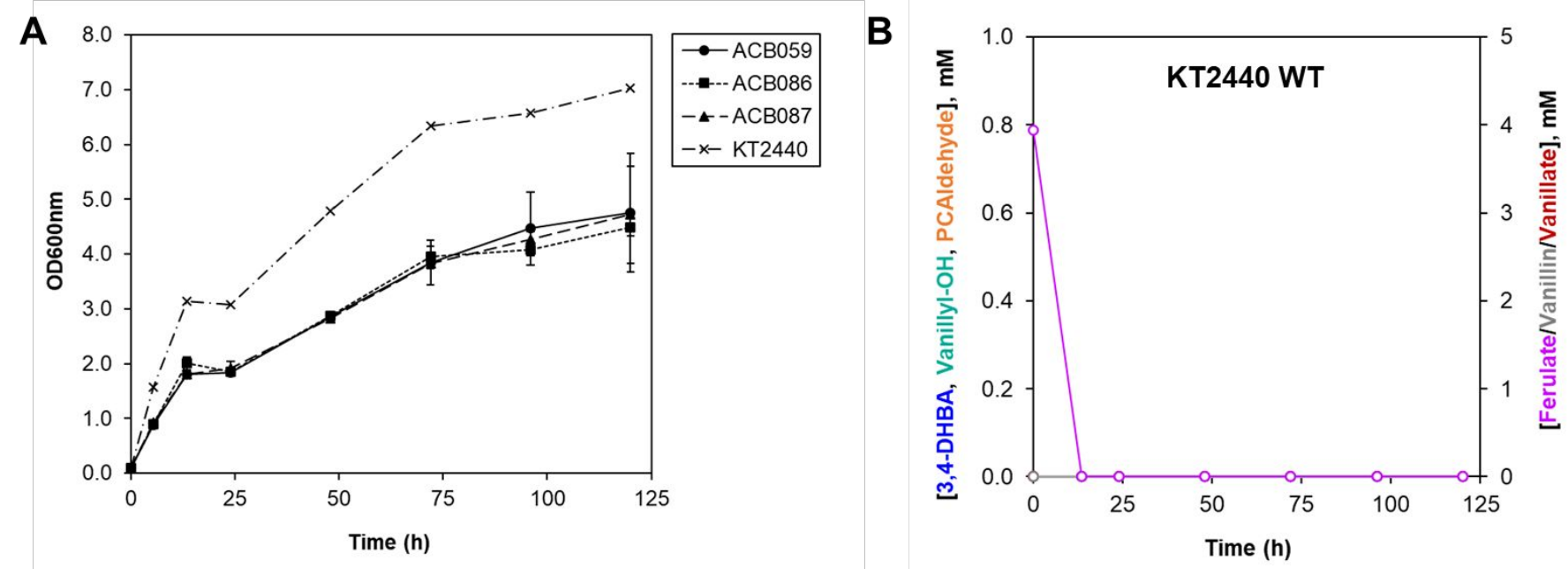

Figure S15. Growth dynamics of engineered $P$. putida strains versus KT2440 wild-type. (A) Cultures were grown in shake flasks with $4 \mathrm{mM}$ ferulate and $10 \mathrm{mM}$ glucose, and glucose was fed every $24 \mathrm{~h}$ to support growth; optical density measurements at $600 \mathrm{~nm}$ determined the cell density of each culture. Error bars indicate the standard deviation from the mean of three replicates. (B) Metabolites quantified from cultures of KT2440 WT (see Figure 5B-D for the other three strains) over the course of growth. Note that only ferulate (pink circles) was detectable for these samples, and only at $0 \mathrm{~h}$. (Abbreviations: Vanillyl-OH, vanillyl alcohol; PCAldehyde, protocatechuic aldehyde; 3,4-DHBA, 3,4-dihydroxybenzyl alcohol.) 
Figure S16

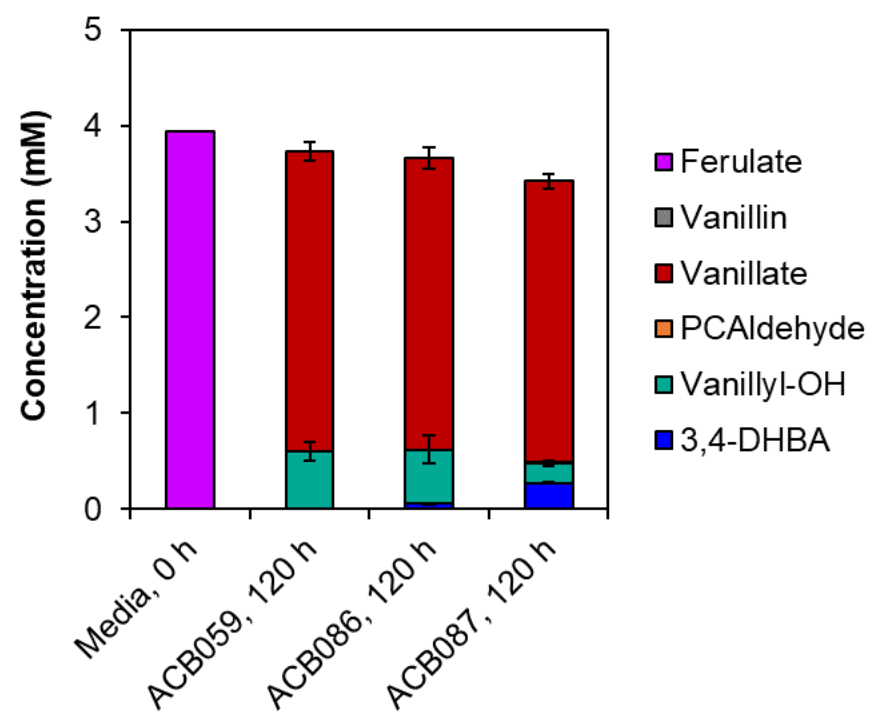

Figure S16. Mole balance of metabolites in engineered $P$. putida strains. Metabolite concentration measurements from culture filtrates (taken after $120 \mathrm{~h}$ of incubation) were compared to the initial medium $(0 \mathrm{~h})$ and summed to generate a mole balance. Error bars indicate the standard deviation from the mean of three replicates. 


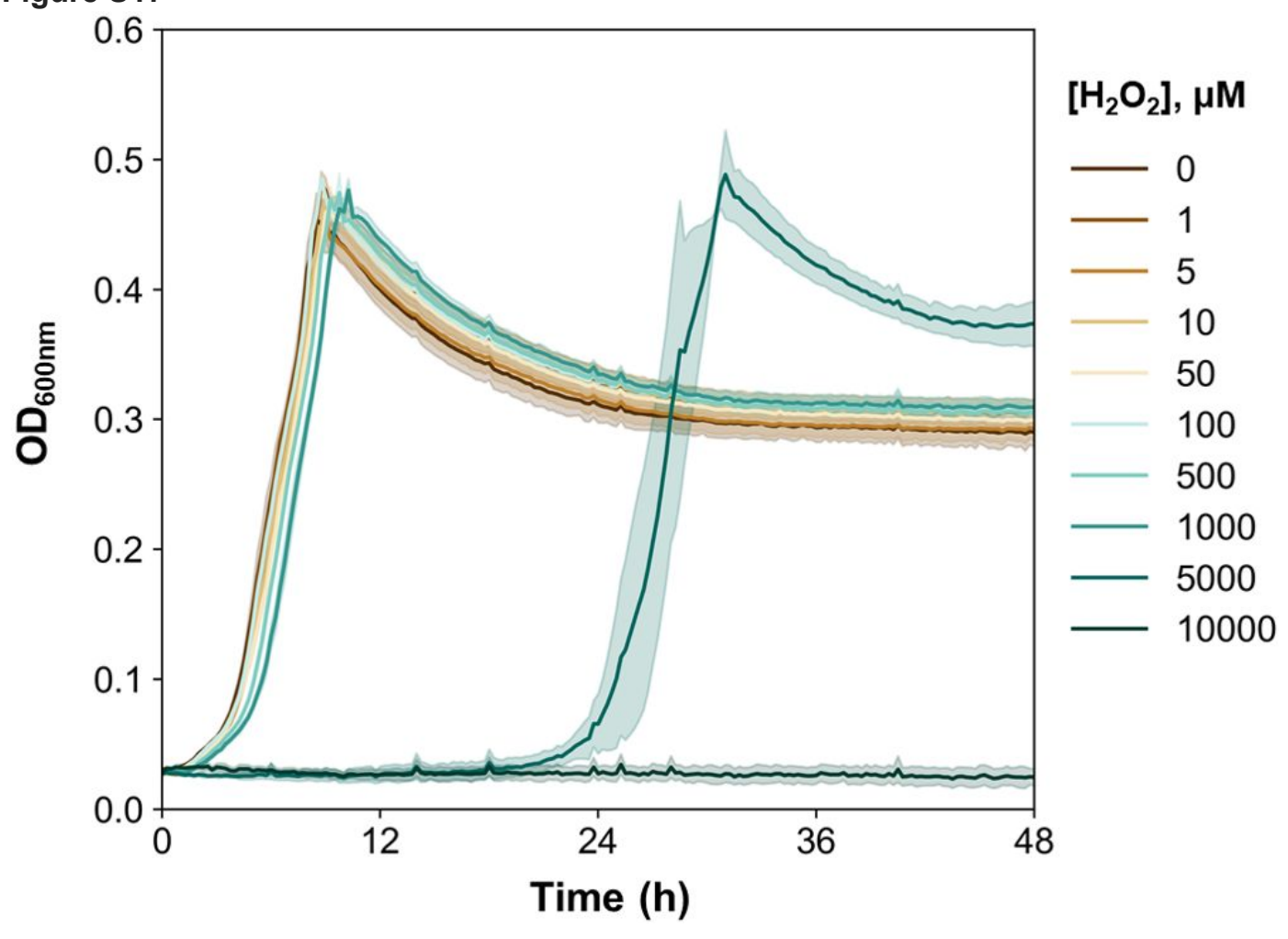

Figure S17. Growth of $P$. putida strain ACB087 under oxidative stress conditions. A preculture of $P$. putida ACB087 was prepared and induced as in Figure 5 (SI Methods; "Shake flask cultivations"), and then the cells were diluted into prepared aliquots of $1 \mathrm{X} \mathrm{M} 9$ media with $4 \mathrm{mM}$ ferulic acid, $10 \mathrm{mM}$ glucose, and the indicated concentrations of hydrogen peroxide $\left(\mathrm{H}_{2} \mathrm{O}_{2}\right)$. Cultures were grown in triplicate in microtiter plates in a Bioscreen $\mathrm{C}$ MBR (Oy Growth Curves Ab Ltd., Helsinki, Finland) at $30^{\circ} \mathrm{C}$ with constant shaking. Error bars indicate the standard deviation from the mean of three replicates, and absorbance measurements are corrected by cell-free media blanks. 


\section{Section 3: Tables}

Table S1. Catalytic efficiencies, ligand affinities, and kinetic properties of GcoA and its variants.

\begin{tabular}{|c|c|c|c|c|c|c|c|c|}
\hline Variant/ & Substrate & $\begin{array}{rr} & \mathrm{v} \\
& \mathrm{c} \\
& \mu \\
K_{\mathrm{D}}(\mu \mathrm{M})^{[\mathrm{a}]} & \mu\end{array}$ & $\begin{array}{l}v_{i} N A D H \\
\text { consumption } \\
\mu \mathrm{M} \mathrm{s}^{-1} \\
\mu \mathrm{M}-E^{-1} z^{-1[b]}\end{array}$ & $\begin{array}{l}v_{i} \text { product } \\
\text { formation } \\
\mu \mathrm{M} \mathrm{s}^{-1} \\
\mu \mathrm{M}-E n z^{-1[b]}\end{array}$ & $\%$-Coupling $[\mathrm{b}]$ & $K_{\mathrm{M}}(\mathrm{mM})^{[\mathrm{c}]}$ & $k_{\text {cat }}\left(\mathrm{s}^{-1}\right)$ & $\begin{array}{l}k_{\text {cat }} / K_{\mathrm{M}} \\
\left(\mathrm{mM}^{-1} \mathrm{~s}^{-1}\right)\end{array}$ \\
\hline \multirow{3}{*}{ WT } & Guaiacol & $0.13+/-0.02$ & 20.96 & 0.72 & $78 \pm 10$ & $\begin{array}{l}0.037 \pm \\
0.008\end{array}$ & $\begin{array}{l}0.57 \pm \\
0.03\end{array}$ & $15 \pm 3$ \\
\hline & o-Vanillin & $28+/-4$ & 0.27 & .023 & $19 \pm 6$ & $0.54 \pm 0.2$ & $\begin{array}{l}0.36 \pm \\
0.09\end{array}$ & $0.7 \pm 0.3$ \\
\hline & $p$-Vanillin & $60+/-4$ & 0.21 & .040 & $6.6 \pm 1$ & $\begin{array}{l}0.27 \pm \\
0.08\end{array}$ & $\begin{array}{l}0.50 \pm \\
0.08\end{array}$ & $1.9 \pm 0.7$ \\
\hline \multirow{3}{*}{ F169S } & Guaiacol & $19+/-0.3$ & 0.28 & 0.13 & $32 \pm 5$ & $\begin{array}{l}0.07 \pm \\
0.02\end{array}$ & $\begin{array}{l}0.40 \pm \\
0.04\end{array}$ & $5.7 \pm 1.7$ \\
\hline & o-Vanillin & $38+/-3$ & 0.21 & 0.072 & $46 \pm 8$ & $\begin{array}{l}0.12 \pm \\
0.04\end{array}$ & $\begin{array}{l}0.37 \pm \\
0.05\end{array}$ & $3.1 \pm 1.1$ \\
\hline & $p$-Vanillin & $\begin{array}{l}\text { does not } \\
\text { bind }\end{array}$ & 0.033 & 0 & 0 & $\mathrm{n} / \mathrm{a}^{[\mathrm{d}]}$ & $\mathrm{n} / \mathrm{a}$ & $\mathrm{n} / \mathrm{a}$ \\
\hline \multirow{3}{*}{ T296S } & Guaiacol & $4.1+/-0.1$ & 0.59 & 0.23 & $48 \pm 6$ & $\begin{array}{l}0.08 \pm \\
0.02\end{array}$ & $\begin{array}{l}0.63 \pm \\
0.07\end{array}$ & $8 \pm 3$ \\
\hline & o-Vanillin & $80+/-10$ & 0.075 & 0 & 0 & $\mathrm{n} / \mathrm{a}$ & $\mathrm{n} / \mathrm{a}$ & $\mathrm{n} / \mathrm{a}$ \\
\hline & $p$-Vanillin & $28+/-2$ & 0.38 & 0.30 & $57 \pm 20$ & $\begin{array}{l}0.05 \pm \\
0.02\end{array}$ & $\begin{array}{l}0.63 \pm \\
0.08\end{array}$ & $13 \pm 5$ \\
\hline \multirow{3}{*}{$\begin{array}{l}\text { F169A/ } \\
\text { T296S }\end{array}$} & Guaiacol & $160+/-4$ & 0.37 & 0.0 & 0 & $\mathrm{n} / \mathrm{a}$ & $\mathrm{n} / \mathrm{a}$ & $\mathrm{n} / \mathrm{a}$ \\
\hline & o-Vanillin & $\begin{array}{l}\text { does not } \\
\text { bind }\end{array}$ & 0.07 & 0.0 & 0 & $\mathrm{n} / \mathrm{a}$ & $\mathrm{n} / \mathrm{a}$ & $\mathrm{n} / \mathrm{a}$ \\
\hline & $p$-Vanillin & $\begin{array}{l}\text { does not } \\
\text { bind }\end{array}$ & 0.47 & 0.046 & 0 & $\mathrm{n} / \mathrm{a}$ & $\mathrm{n} / \mathrm{a}$ & $\mathrm{n} / \mathrm{a}$ \\
\hline
\end{tabular}

[a] $\mathrm{K}_{\mathrm{D}}$ was measured by titrating $0-60 \mu \mathrm{M}$ of substrate into a solution containing 2-6 $\mu \mathrm{M}$ GcoAB in air-saturated

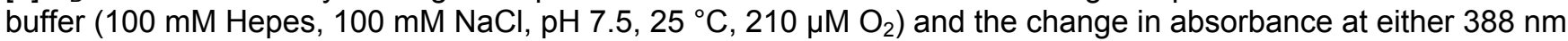
(guaiacol) or $570 \mathrm{~nm}$ (o- and $p$-vanillin) was plotted as a function of substrate concentration and fit to [Equation S1]. [b] Initial rates of NADH consumption and \%-coupling of substrate demethylation to NADH consumption were measured simultaneously (see Fig 2 and Fig S2A). [c] The Michaelis constants are apparent, as the dioxygen and GcoB concentrations are not known to be saturating. The conditions used were $0.5 \mu \mathrm{M}$ GcoAB, $100 \mu \mathrm{g} / \mathrm{mL}$ catalase, $300 \mu \mathrm{M} \mathrm{NADH}$, and 0-500 $\mu \mathrm{M}$ substrate, in air-saturated buffer $(25 \mathrm{mM} \mathrm{HEPES}, 50 \mathrm{mM} \mathrm{NaCl}, \mathrm{pH} 7.5)$ at $25^{\circ} \mathrm{C}$. [d] Michaelis constants for some substrate/enzyme combinations were not measured because of a high level of NADH uncoupling or low amount of substrate turnover, indicated by n/a. 
Table S2. X-ray tables for GcoA guaiacol-bound structures.

\begin{tabular}{|c|c|c|c|}
\hline Protein & T296A with guaiacol & T296G with guaiacol & T296S with guaiacol \\
\hline PDB code & $6 \mathrm{YCH}$ & $6 \mathrm{YCl}$ & $6 Y C J$ \\
\hline Wavelength (A) & 0.9795 & 0.9795 & 0.9795 \\
\hline Resolution range $(\AA)$ & $52.08-1.88(1.95-1.88)$ & $47.52-1.80(1.86-1.80)$ & $62.29-1.64(1.70-1.64)$ \\
\hline Space group & $P 4_{3} 2_{1} 2$ & $P 4_{3} 2_{1} 2$ & $P 4_{3} 2_{1} 2$ \\
\hline Unit cell a,b,c (A), $\alpha, \beta, y(\circ)$ & $\begin{array}{c}104.162104 .162115 .699090 \\
90\end{array}$ & $\begin{array}{c}104.065104 .065116 .7319090 \\
90\end{array}$ & $\begin{array}{c}103.978103 .978117 .229090 \\
90\end{array}$ \\
\hline Total reflections & $668864(67212)$ & $120043(11768)$ & $1009618(98975)$ \\
\hline Unique reflections & $52312(5135)$ & $60026(5887)$ & 78998 (7758) \\
\hline Multiplicity & $12.8(13.1)$ & $2.0(2.0)$ & $12.8(12.8)$ \\
\hline Completeness (\%) & $99.58(98.99)$ & $99.88(99.12)$ & $99.37(97.62)$ \\
\hline Mean I/sigma(I) & $18.15(2.72)$ & $26.18(4.75)$ & $19.51(2.17)$ \\
\hline Wilson B-factor & 24.89 & 28.33 & 21.69 \\
\hline R-merge & $0.08069(0.9317)$ & $0.01461(0.1535)$ & $0.06269(1.261)$ \\
\hline R-meas & $0.08407(0.9697)$ & $0.02067(0.217)$ & $0.06532(1.313)$ \\
\hline R-pim & $0.02334(0.2668)$ & $0.01461(0.1535)$ & $0.01819(0.3645)$ \\
\hline $\mathrm{CC} 1 / 2$ & $1(0.862)$ & $1(0.957)$ & $1(0.858)$ \\
\hline $\mathrm{CC}^{*}$ & $1(0.962)$ & $1(0.989)$ & $1(0.961)$ \\
\hline Reflections used in refinement & $52312(5085)$ & $60015(5885)$ & 78998 (7601) \\
\hline Reflections used for R-free & $2568(247)$ & $2915(287)$ & $3972(384)$ \\
\hline R-work & $0.1885(0.3203)$ & $0.1658(0.2423)$ & $0.1918(0.3786)$ \\
\hline R-free & $0.2117(0.3616)$ & $0.1872(0.2711)$ & $0.2130(0.3833)$ \\
\hline CC(work) & $0.973(0.849)$ & $0.971(0.925)$ & $0.974(0.884)$ \\
\hline $\mathrm{CC}($ free $)$ & $0.962(0.760)$ & $0.978(0.877)$ & $0.964(0.871)$ \\
\hline $\begin{array}{l}\text { Number of non-hydrogen } \\
\text { atoms }\end{array}$ & 3686 & 3577 & 3720 \\
\hline macromolecules & 3163 & 3168 & 3174 \\
\hline Ligands & 67 & 52 & 52 \\
\hline Solvent & 456 & 357 & 494 \\
\hline Protein residues & 403 & 403 & 403 \\
\hline RMS(bonds) (A) & 0.008 & 0.01 & 0.007 \\
\hline RMS(angles) (॰) & 1.32 & 1.41 & 1.26 \\
\hline Ramachandran favored (\%) & 97 & 96.76 & 97.01 \\
\hline Ramachandran allowed (\%) & 2.75 & 2.99 & 2.74 \\
\hline Ramachandran outliers (\%) & 0.25 & 0.25 & 0.25 \\
\hline Rotamer outliers (\%) & 0 & 1.81 & 0 \\
\hline Clashscore & 2.06 & 1.43 & 1.59 \\
\hline Average B-factor & 30.35 & 36.79 & 28.4 \\
\hline Macromolecules & 29.19 & 36.39 & 27.17 \\
\hline Ligands & 27.13 & 25.84 & 18.01 \\
\hline Solvent & 38.86 & 42.01 & 37.34 \\
\hline
\end{tabular}

Statistics for the highest-resolution shell are shown in parentheses. 
Table S3. X-ray tables for GcoA p-vanillin-bound structures.

\begin{tabular}{|c|c|c|c|c|}
\hline & T296A with p-vanillin & T296G with p-vanillin & T296S with p-vanillin & $\begin{array}{l}\mathrm{F} 169 \mathrm{~A} / \mathrm{T} 296 \mathrm{~S} \text { with } \mathrm{p}- \\
\text { vanillin }\end{array}$ \\
\hline PDB code & $6 Y C K$ & $6 Y C L$ & $6 Y C M$ & $6 Y C T$ \\
\hline Wavelength $(\AA)$ & 0.9763 & 0.9795 & 0.9795 & 0.9159 \\
\hline Resolution range $(\AA)$ & $28.28-1.80(1.87-1.80)$ & $46.52-1.70(1.76-1.70)$ & $52.02-1.6(1.66-1.60)$ & $47.41-2.39(2.48-2.39)$ \\
\hline Space group & $P 4_{3} 2_{1} 2$ & $P 4_{3} 2_{1} 2$ & $P 4_{3} 2_{1} 2$ & $P 4_{3} 2_{1} 2$ \\
\hline $\begin{array}{l}\text { Unit cell a,b,c }(\AA), \\
\alpha, \beta, \gamma\left({ }^{\circ}\right) \\
\text { Total reflections }\end{array}$ & $\begin{array}{c}105.101105 .101113 .135 \\
909090 \\
117999(11481)\end{array}$ & $\begin{array}{c}104.021104 .021116 .87 \\
909090 \\
141509(13921)\end{array}$ & $\begin{array}{c}104.036104 .036116 .842 \\
909090 \\
1085533(107594)\end{array}$ & $\begin{array}{c}104.07104 .07115 .08290 \\
9090 \\
50932(4890)\end{array}$ \\
\hline Unique reflections & $59013(5753)$ & $70762(6961)$ & 84765 (8286) & $25466(2445)$ \\
\hline Multiplicity & $2.0(2.0)$ & $2.0(2.0)$ & $12.8(13.0)$ & $2.0(2.0)$ \\
\hline Completeness (\%) & $99.82(98.71)$ & $99.97(99.94)$ & $99.00(96.89)$ & $99.76(97.88)$ \\
\hline Mean I/sigma(I) & $38.36(4.96)$ & $25.90(4.55)$ & $20.51(2.47)$ & $25.64(6.03)$ \\
\hline Wilson B-factor & 33.94 & 27.91 & 22.20 & 36.53 \\
\hline R-merge & $0.01109(0.1496)$ & $0.01492(0.1696)$ & $0.05153(1.118)$ & $0.02076(0.126)$ \\
\hline R-meas & $0.01568(0.2116)$ & $0.0211(0.2398)$ & $0.0537(1.164)$ & $0.02936(0.1782)$ \\
\hline R-pim & $0.01109(0.1496)$ & $0.01492(0.1696)$ & $0.01497(0.3198)$ & $0.02076(0.126)$ \\
\hline $\mathrm{CC} 1 / 2$ & $1(0.943)$ & $1(0.956)$ & $1(0.898)$ & $0.999(0.954)$ \\
\hline $\mathrm{CC}^{*}$ & $1(0.985)$ & $1(0.989)$ & $1(0.973)$ & $1(0.988)$ \\
\hline $\begin{array}{l}\text { Reflections used in } \\
\text { refinement }\end{array}$ & $59011(5753)$ & $70751(6960)$ & $83940(8077)$ & $25466(2444)$ \\
\hline $\begin{array}{l}\text { Reflections used for R- } \\
\text { free }\end{array}$ & $3002(321)$ & $3528(332)$ & $4142(419)$ & $1217(112)$ \\
\hline R-work & $0.1605(0.2068)$ & $0.1652(0.2641)$ & $0.1976(0.3582)$ & $0.1580(0.1932)$ \\
\hline R-free & $0.1803(0.2372)$ & $0.1844(0.2884)$ & $0.2264(0.3580)$ & $0.1974(0.1942)$ \\
\hline CC(work) & $0.974(0.925)$ & $0.973(0.933)$ & $0.973(0.894)$ & $0.972(0.916)$ \\
\hline CC(free) & $0.970(0.915)$ & $0.961(0.906)$ & $0.968(0.889)$ & $0.964(0.923)$ \\
\hline $\begin{array}{l}\text { Number of non- } \\
\text { hydrogen atoms }\end{array}$ & 3641 & 3578 & 3703 & 3384 \\
\hline Macromolecules & 3205 & 3180 & 3160 & 3169 \\
\hline Ligands & 69 & 54 & 54 & 69 \\
\hline Solvent & 367 & 344 & 489 & 146 \\
\hline Protein residues & 403 & 403 & 402 & 403 \\
\hline RMS(bonds) (Â) & 0.007 & 0.011 & 0.006 & 0.008 \\
\hline RMS(angles) ( $\left.{ }^{\circ}\right)$ & 1.31 & 1.33 & 0.91 & 1.31 \\
\hline $\begin{array}{l}\text { Ramachandran favored } \\
(\%)\end{array}$ & 96.76 & 97.01 & 97.25 & 96.76 \\
\hline $\begin{array}{l}\text { Ramachandran allowed } \\
(\%)\end{array}$ & 2.99 & 2.74 & 2.50 & 2.99 \\
\hline $\begin{array}{l}\text { Ramachandran outliers } \\
(\%)\end{array}$ & 0.25 & 0.25 & 0.25 & 0.25 \\
\hline Rotamer outliers (\%) & 0.3 & 0.9 & 0.31 & 0 \\
\hline Clashscore & 2.81 & 1.27 & 1.92 & 2.37 \\
\hline Average B-factor & 36.52 & 37.76 & 30.01 & 38.15 \\
\hline macromolecules & 35.67 & 37.25 & 28.75 & 38.15 \\
\hline Ligands & 34.35 & 26.66 & 20.32 & 34.73 \\
\hline Solvent & 44.43 & 44.19 & 39.16 & 39.94 \\
\hline
\end{tabular}

Statistics for the highest-resolution shell are shown in parentheses. 
Table S4. X-ray tables for GcoA o-vanillin-bound structures.

F169A with o-vanillin

PDB code
Wavelength (A)
Resolution range $(A)$
Space group
Unit cell a,b,c $(A), \alpha, \beta, Y()^{\circ}$
Total reflections
Unique reflections
Multiplicity
Completeness (\%)
Mean l/sigma(I)
Wilson B-factor
R-merge
R-meas
R-pim
CC1/2
CC*
Reflections used in refinement
Reflections used for R-free
R-work
R-free
CC(work)
CC(free)

Number of non-hydrogen atoms

macromolecules

Ligands

Solvent

Protein residues

RMS(bonds) (A)

RMS(angles) ( $\circ$ )

Ramachandran favored (\%)

Ramachandran allowed (\%)

Ramachandran outliers (\%)

Rotamer outliers (\%)

Clashscore

Average B-factor

macromolecules

Ligands

Solvent

$6 Y C N$
0.9795
$46.66-1.83(1.90-1.83)$
$P 4_{3} 2_{1} 2$

104.328104 .328115 .0259090

$$
\begin{gathered}
90 \\
112889(11060) \\
56447(5530) \\
2.0(2.0) \\
99.94(99.60) \\
31.96(5.17) \\
33.56
\end{gathered}
$$

$0.01277(0.1503)$

$0.01806(0.2125)$

$0.01277(0.1503)$

$1(0.943)$

$1(0.985)$

56443 (5529)

2897 (308)

$0.1563(0.2048)$

$0.1789(0.2288)$

$0.971(0.918)$

$0.957(0.892)$

3546

3165

54

327

403

0.011

1.33

96.51

3.24

0.25

0.3

1.11

37.79

37.34

27.43

43.8
F169S with o-vanillin

$\begin{array}{cc}6 Y \mathrm{YCO} & 6 \mathrm{YCP} \\ 0.9795 & 0.9795 \\ 46.56-1.80(1.861-1.80) & 47.48-1.80(1.864-1.80) \\ P 4_{3} 2_{1} 2 & P 4_{3} 2_{1} 2\end{array}$

104.117 104.117115.7639090

90
$119252(11564)$

59632 (5784)

$$
2.0(2.0)
$$

99.82 (98.28)

24.59 (6.74)

22.97

0.01893 (0.1149)

$0.02677(0.1625)$

0.01893 (0.1149)

0.999 (0.956)

1 (0.989)

59631 (5784)

2896 (283)

$0.1416(0.1622)$

$0.1606(0.1989)$

0.971 (0.946)

0.968 (0.888)

$$
3607
$$

3166

54

387

403

0.009

1.37

97.01

2.74

0.25

0.6

1.75

26.31

25.23

17

36.4
104.193104 .193115 .3349090

$$
90
$$

118708 (11617)

59357 (5809)

$$
2.0(2.0)
$$

99.93 (99.54)

28.19 (5.06)

31.45

$0.01332(0.1377)$

$0.01884(0.1947)$

$0.01332(0.1377)$

$$
1(0.947)
$$

1 (0.986)

59353 (5808)

2985 (295)

$0.1617(0.2190)$

$0.1831(0.2645)$

$0.973(0.902)$

$0.966(0.839)$

\begin{tabular}{c}
3555 \\
3167 \\
54 \\
334 \\
403 \\
0.01 \\
1.43 \\
96.51 \\
3.24 \\
0.25 \\
1.2 \\
2.39 \\
35.39 \\
34.89 \\
24.31 \\
41.92 \\
\hline
\end{tabular}

Statistics for the highest-resolution shell are shown in parentheses. 
Table S5. Strain construction details.

\begin{tabular}{|c|c|c|}
\hline Strain & Genotype & Source / Construction Details \\
\hline KT2440 & P. putida KT2440 wild-type & ATCC 47054 \\
\hline GN442 & 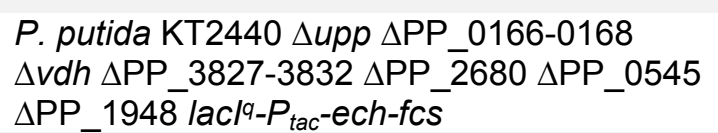 & (31) \\
\hline ACB059 & P. putida GN442:: $\Delta$ vanAB & $\begin{array}{l}\text { This study. vanAB was deleted from } P \text {. } \\
\text { putida GN442 with pSN066. Gene deletion } \\
\text { was confirmed by colony PCR with } \\
\text { oSN103/oSN226, which resulted in a } 1201 \\
\text { bp product. }\end{array}$ \\
\hline$A C B 070$ & $\begin{array}{l}\text { P. putida ACB059::catA:gcoAB (catA-gcoA } \\
\text { fusion) }\end{array}$ & $\begin{array}{l}\text { This study. cat } A \text { was replaced by catA- } \\
\text { gco } A B \text { with pACB028, such that cat } A \text { and } \\
\text { gco } A \text { were fused as in Tumen-Velasquez et } \\
\text { al. ( } 32 \text { ) Insertion was confirmed by colony } \\
\text { PCR with oACB } 033 / \text { oACB } 139 \text {, which } \\
\text { resulted in a } 1923 \text { bp product. }\end{array}$ \\
\hline$A C B 071$ & $\begin{array}{l}\text { P. putida ACB059::catA:gcoA[T296S]B } \\
\text { (catA-gcoA[T296S] fusion) }\end{array}$ & $\begin{array}{l}\text { This study. cat } A \text { was replaced by catA- } \\
\text { gcoA[T296S]B with pACB029, such that } \\
\text { catA and gcoA[T296S] were fused as in } \\
\text { Tumen-Velasquez et al. (32) Insertion was } \\
\text { confirmed by colony PCR with } \\
\text { oACB033/oACB139, which resulted in a } \\
1923 \text { bp product. }\end{array}$ \\
\hline ACB086 & $\begin{array}{l}\text { P. putida ACB059::Ptac:catA:gcoAB (catA- } \\
\text { gcoA fusion) }\end{array}$ & $\begin{array}{l}\text { This study. Insertion of the strong Ptac } \\
\text { promoter upstream of catA was achieved } \\
\text { with pACB049 and confirmed by colony } \\
\text { PCR with oACB194/OACB195, which } \\
\text { resulted in a } 1074 \text { bp product. Sanger } \\
\text { sequencing with oACB193 further confirmed } \\
\text { the insertion. }\end{array}$ \\
\hline ACB087 & $\begin{array}{l}\text { P. putida ACB059::Ptac:catA:gcoA[T296S]B } \\
\text { (catA-gcoA[T296S] fusion) }\end{array}$ & $\begin{array}{l}\text { This study. Insertion of the strong Ptac } \\
\text { promoter upstream of catA was achieved } \\
\text { with pACB0 } 49 \text { and confirmed by colony } \\
\text { PCR with oACB194/oACB195, which } \\
\text { resulted in a } 1074 \text { bp product. Sanger } \\
\text { sequencing with oACB193 further confirmed } \\
\text { the insertion. }\end{array}$ \\
\hline
\end{tabular}


Table S6. Primers used in construction of plasmids.

\begin{tabular}{|c|c|}
\hline Primer & Sequence (5'-3') \\
\hline oSN099 & AGTGAGCGCAACGCAATTAATGTGAGTTAGGAATTCATGGCGCCGCCAGTG \\
\hline oSN103 & CCACTGCGCCAGCGACGC \\
\hline oSN223 & GAAAGTCATCCTGCCСTCGTCGTAAGACGGGGCGGCCGCGGGAGGCTCTCCGGG \\
\hline oSN224 & $\begin{array}{l}\text { TAAATAAAAACAAAACCCGGAGAGCCTCCCGCGGCCGCCCCGTCTTACGACGAGGG } \\
\text { C }\end{array}$ \\
\hline oSN225 & $\begin{array}{l}\text { CCTGAGTGCTTGCGGCAGCGTGAAGCTAGGGATCCGAGGTGAACTACACCTTCCAG } \\
\text { AGC }\end{array}$ \\
\hline oSN226 & GCTTCAGGCGAGTTGGCG \\
\hline оАСВ033 & CCAGATCGGCGAGGTCCACCG \\
\hline oACB134 & CATAACCTCGAACCACTGAGCCTCCACCTAG \\
\hline oACB135 & TGGGAGGTGTGAGAAGTGCCATTCCGCCTG \\
\hline oACB136 & GGAATGGCACTTCTCACACCTCCCAGGTGAC \\
\hline oACB137 & CCAGTGCCAAGCTTGCATGCCTGCAATGACCGTGAAAATTTCCCAC \\
\hline oACB138 & TCGGCCTCAGCCCGCATCTC \\
\hline oACB139 & TCGAGGCATTGCATGACAC \\
\hline oACB140 & CATGATTACGAATTCGAGCTGGCATCGGTGTAGAACAAC \\
\hline oACB141 & CTCAGTGGTTCGAGGTTATGGTTCGAGGTTATGTCACTG \\
\hline oACB189 & CCAGTGCCAAGCTTGCATGCCTGCAGTGCGGGTCGACGTCAAC \\
\hline oACB190 & $\begin{array}{l}\text { GCTGTGTGAAATTGTTATCCGCTCACAATTCCACACATTATACGAGCCGATGATTAAT } \\
\text { TGTCAACAGCTCCGTGCTTACCTCGTATTGTTCTTGTCAGG }\end{array}$ \\
\hline oACB191 & $\begin{array}{l}\text { GTGAGCGGATAACAATTTCACACAGCGACCACTTAAAGGGACCCCACCGACCCTAA } \\
\text { TCCGTAAGGATCAGATCATGACCGTGAAAATTTCCCACACTGCCG }\end{array}$ \\
\hline OACB192 & TATGACATGATTACGAATTCGAGCTCGTCAGGCGACTTGGCACC \\
\hline oACB193 & GTCAGTGCCGTCGTCCATG \\
\hline oACB194 & CCTTTAAGTGGTCGCTGTG \\
\hline OACB195 & CACCGCGTGTTCAAGCTG \\
\hline
\end{tabular}


Table S7. Plasmids and construction details.

\begin{tabular}{|c|c|c|}
\hline Plasmid & Purpose & Construction details \\
\hline pSN066 & Deletion of $v a n A B$ in genome of ACB059 & $\begin{array}{l}\text { Genomic homology regions upstream and } \\
\text { downstream of van } A B \text { were amplified from } \\
P . \text { putida KT2440 gDNA with } \\
\text { oSN099/oSN223 and oSN224/oSN225, } \\
\text { respectively. These products were } \\
\text { assembled by the method of Gibson into } \\
\text { pK18mobsacB (GenBank: FJ437239.1). }\end{array}$ \\
\hline$p A C B 028$ & $\begin{array}{l}\text { Insertion of gcoAB downstream of } c a t A \\
\text { (with } c a t A-g c o A \text { expressed as a fusion } \\
\text { protein) in } P \text {. putida ACB } 070\end{array}$ & $\begin{array}{l}\text { The cat } A \text {-gco } A \text { fusion was amplified from } \\
\text { pCJ126 (32) with oACB136/oACB137; the } \\
\text { genomic homology region downstream of } \\
\text { catA was amplified from } P \text {. putida KT } 2440 \\
\text { gDNA with oACB140/oACB141. These } \\
\text { products were assembled by the method of } \\
\text { Gibson into pK18sb (Genbank: } \\
\text { MH166772) digested with SacI and PstI. }\end{array}$ \\
\hline$p A C B 029$ & $\begin{array}{l}\text { Insertion of } g c o A[\mathrm{~T} 296 \mathrm{~S}] B \text { downstream of } \\
\text { cat } A \text { (with } \operatorname{cat} A-g c o A[\mathrm{~T} 296 \mathrm{~S}] \text { expressed as } \\
\text { a fusion protein) in } P \text {. putida ACB } 071\end{array}$ & $\begin{array}{l}\text { pACB028 was amplified with site directed } \\
\text { mutagenesis primers oACB } 138 / \text { oACB } 033 \\
\text { to introduce the T296S codon change, and } \\
\text { the product was treated with KLD Enzyme } \\
\text { Mix (New England Biolabs) to re- } \\
\text { circularize the plasmid. }\end{array}$ \\
\hline$p A C B 049$ & $\begin{array}{l}\text { Insertion of Ptac promoter upstream of } \\
\text { catA in } P \text {. putida ACB } 086 \text { and ACB } 087\end{array}$ & $\begin{array}{l}\text { Genomic homology regions up- and } \\
\text { downstream of the } 5 \text { ' end of cat } A \text { were } \\
\text { amplified from } P \text {. putida KT } 2440 \text { gDNA } \\
\text { with oACB189/190 and oACB191/192, } \\
\text { respectively. Oligos oACB190 and } \\
\text { oACB191 were designed as Ultramers } \AA \\
\text { (Integrated DNA Technologies, Inc; } \\
\text { Coralville, IA) to incorporate the Ptac } \\
\text { promoter and RBS for cat } A \text {-gcoA upstream } \\
\text { of } c a t A \text {. The products were assembled by } \\
\text { the method of Gibson into pK18sb } \\
\text { (Genbank: MH166772) digested with SacI } \\
\text { and PstI. }\end{array}$ \\
\hline
\end{tabular}




\section{References}

(1) Machovina, M. M.; Mallinson, S. J.; Knott, B. C.; Meyers, A. W.; Garcia-Borràs, M.; Bu, L.; Gado, J. E.; Oliver, A.; Schmidt, G. P.; Hinchen, D. J., Enabling Microbial Syringol Conversion through Structure-Guided Protein Engineering. Proc. Natl. Acad. Sci. 2019, 116 (28), 13970-13976.

(2) Guengerich, F. P.; Martin, M. V.; Sohl, C. D.; Cheng, Q., Measurement of Cytochrome P450 and Nadph-Cytochrome P450 Reductase. Nat. Protoc. 2009, 4 (9), 1245-1251.

(3) Chrastil, J.; Wilson, J. T., A Sensitive Colorimetric Method for Formaldehyde. Anal. Biochem. 1974, 63 (1), 202-207.

(4) Mallinson, S. J.; Machovina, M. M.; Silveira, R. L.; Garcia-Borràs, M.; Gallup, N.; Johnson, C. W.; Allen, M. D.; Skaf, M. S.; Crowley, M. F.; Neidle, E. L., A Promiscuous Cytochrome P450 Aromatic O-Demethylase for Lignin Bioconversion. Nat. Commun. 2018, 9 (1), 1-12.

(5) Evans, P. R., An Introduction to Data Reduction: Space-Group Determination, Scaling and Intensity Statistics. Acta Crystallogr. D Biol. Crystallogr. 2011, 67 (4), 282-292.

(6) Evans, P. R., Scaling and Assessment of Data Quality. Acta Crystallogr. D Biol. Crystallogr. 2006, $62(1), 72-82$.

(7) Winter, G., Xia2: An Expert System for Macromolecular Crystallography Data Reduction. J. Appl. Crystallogr. 2010, 43 (1), 186-190.

(8) Padilla, J. E.; Yeates, T. O., A Statistic for Local Intensity Differences: Robustness to Anisotropy and Pseudo-Centering and Utility for Detecting Twinning. Acta Crystallogr. D Biol. Crystallogr. 2003, 59 (7), 1124-1130.

(9) Kabsch, W., Xds. Acta Crystallogr. D Biol. Crystallogr. 2010, 66 (2), 125-132.

(10) Terwilliger, T. C.; Grosse-Kunstleve, R. W.; Afonine, P. V.; Moriarty, N. W.; Zwart, P. H.; Hung, L. W.; Read, R. J.; Adams, P. D., Iterative Model Building, Structure Refinement and Density Modification with the Phenix Autobuild Wizard. Acta Crystallogr. D Biol. Crystallogr. 2007, 64 (1), 61-69.

(11) Adams, P. D.; Afonine, P. V.; Bunkoczi, G.; Chen, V. B.; Davis, I. W.; Echols, N.; Headd, J. J.; Hung, L. W.; Kapral, G. J.; Grosse-Kunstleve, R. W.; McCoy, A. J.; Moriarty, N. W.; Oeffner, R.; Read, R. J.; Richardson, D. C.; Richardson, J. S.; Terwilliger, T. C.; Zwart, P. H., Phenix: A Comprehensive Python-Based System for Macromolecular Structure Solution. Acta Crystallogr. D Biol. Crystallogr. 2010, 66 (2), 213-221.

(12) Afonine, P. V.; Grosse-Kunstleve, R. W.; Echols, N.; Headd, J. J.; Moriarty, N. W.; Mustyakimov, M.; Terwilliger, T. C.; Urzhumtsev, A.; Zwart, P. H.; Adams, P. D., Towards Automated Crystallographic Structure Refinement with Phenix.Refine. Acta Crystallogr. D Biol. Crystallogr. 2012, 68 (4), 352-367.

(13) Emsley, P.; Cowtan, K., Coot: Model-Building Tools for Molecular Graphics. Acta Crystallogr. D Biol. Crystallogr. 2004, 60 (12), 2126-2132.

(14) The Pymol Molecular Graphics System, Schrödinger, LLC.

(15) Gordon, J. C.; Myers, J. B.; Folta, T.; Shoja, V.; Heath, L. S.; Onufriev, A., H++: A Server for Estimating Pkas and Adding Missing Hydrogens to Macromolecules. Nucleic Acids Res. 2005, 33 (2), 368-371.

(16) Myers, J.; Grothaus, G.; Narayanan, S.; Onufriev, A., A Simple Clustering Algorithm Can Be Accurate Enough for Use in Calculations of Pks in Macromolecules. Proteins: Structure, Function and Genetics 2006, 63 (4), 928-938.

(17) Maier, J. A.; Martinez, C.; Kasavajhala, K.; Wickstrom, L.; Hauser, K. E.; Simmerling, C., Ff14sb: Improving the Accuracy of Protein Side Chain and Backbone Parameters from Ff99sb. J. Chem. Theory Comput. 2015, 11 (8), 3696-3713.

(18) Wang, J.; Wang, W.; Kollman, P. A.; Case, D. A., Automatic Atom Type and Bond Type Perception in Molecular Mechanical Calculations. J. Mol. Graph. Model. 2006, 25 (2), 247-260. 
(19) Wang, J.; Wolf, R. M.; Caldwell, J. W.; Kollman, P. A.; Case, D. A., Development and Testing of a General Amber Force Field. J. Comput. Chem. 2004, 25 (9), 1157-1174.

(20) Bayly, C. I.; Cieplak, P.; Cornell, W.; Kollman, P. A., A Well-Behaved Electrostatic Potential Based Method Using Charge Restraints for Deriving Atomic Charges: The Resp Model. J. Phys. Chem. 1993, 97 (40), 10269-10280.

(21) Frisch, M. Gaussian 09, Gaussian, Inc.: Wallingford, CT, 2009.

(22) Shahrokh, K.; Orendt, A.; Yost, G. S.; Cheatham, T. E., 3rd, Quantum Mechanically Derived Amber-Compatible Heme Parameters for Various States of the Cytochrome P450 Catalytic Cycle. J. Comput. Chem. 2012, 33 (2), 119-133.

(23) Phillips, J. C.; Braun, R.; Wang, W.; Gumbart, J.; Tajkhorshid, E.; Villa, E.; Chipot, C.; Skeel, R. D.; Kale, L.; Schulten, K., Scalable Molecular Dynamics with Namd. J. Comput. Chem. 2005, 26 (16), 1781-1802.

(24) Darden, T.; York, D.; Pedersen, L., Particle Mesh Ewald: Ann·Log(N) Method for Ewald Sums in Large Systems. J. Chem. Phys. 1993, 98 (12), 10089-10092.

(25) Kräutler, V.; Van Gunsteren, W. F.; Hünenberger, P. H., A Fast Shake Algorithm to Solve Distance Constraint Equations for Small Molecules in Molecular Dynamics Simulations. J. Comput. Chem. 2001, 22 (5), 501-508.

(26) Martyna, G. J.; Tobias, D. J.; Klein, M. L., Constant Pressure Molecular Dynamics Algorithms. J. Chem. Phys. 1994, 101 (5), 4177-4189.

(27) Feller, S. E.; Zhang, Y.; Pastor, R. W.; Brooks, B. R., Constant Pressure Molecular Dynamics Simulation: The Langevin Piston Method. J. Chem. Phys. 1995, 103 (11), 4613-4621.

(28) Choi, K. H.; Kumar, A.; Schweizer, H. P., A 10-Min Method for Preparation of Highly Electrocompetent Pseudomonas Aeruginosa Cells: Application for DNA Fragment Transfer between Chromosomes and Plasmid Transformation. J. Microbiol. Methods 2006, 64 (3), 391397.

(29) Blomfield, I. C.; Vaughn, V.; Rest, R. F.; Eisenstein, B. I., Allelic Exchange in Escherichia Coli Using the Bacillus Subtilis Sacb Gene and a Temperature-Sensitive Psc101 Replicon. Mol. Microbiol. 1991, 5 (6), 1447-1457.

(30) Johnson, C. W.; Beckham, G. T., Aromatic Catabolic Pathway Selection for Optimal Production of Pyruvate and Lactate from Lignin. Metab. Eng. 2015, 28, 240-247.

(31) Graf, N.; Altenbuchner, J., Genetic Engineering of Pseudomonas Putida Kt2440 for Rapid and High-Yield Production of Vanillin from Ferulic Acid. Appl. Microbiol. Biotech. 2014, 98 (1), 137149.

(32) Tumen-Velasquez, M.; Johnson, C. W.; Ahmed, A.; Dominick, G.; Fulk, E. M.; Khanna, P.; Lee, S. A.; Schmidt, A. L.; Linger, J. G.; Eiteman, M. A., Accelerating Pathway Evolution by Increasing the Gene Dosage of Chromosomal Segments. Proc. Natl. Acad. Sci. 2018, 115 (27), 7105-7110. 